\title{
Bubbles in Food Commodity Markets: Four Decades of Evidence
}

\author{
Xiaoli L. Etienne, Scott H. Irwin, and Philip Garcia ${ }^{1}$
}

March 2013

Paper prepared for presentation at the Conference on "Understanding International Commodity Price Fluctuations” to be held at the International Monetary Fund in Washington, D.C., March, 20-21, 2013

\footnotetext{
${ }^{1}$ Xiaoli Etienne is a doctoral student, Scott H. Irwin is the Laurence J. Norton Chair of Agricultural Marketing, and Philip Garcia is the T.A. Hieronymus Distinguished Chair in Futures Markets, all in the Department of Agricultural and Consumer Economics, University of Illinois at Urbana-Champaign.
} 


\title{
Bubbles in Food Commodity Markets: Four Decades of Evidence
}

\begin{abstract}
We use the daily prices from individual futures contracts to test whether speculative bubbles exist in agricultural futures markets and identify whether patterns of bubble behavior exist over time. Test results demonstrate that all 12 agricultural markets experienced multiple periods of price explosiveness. However, bubble episodes only represent a very small portion of the price behavior for the 42-year period. In addition, most of the bubbles are short-lived, lasting fewer than 20 days. We also find that explosive periods are more common with longer durations in the first half of the sample period, indicating that the most recent bubble episodes may not have been as severe as the mid-1970s episode. Though receiving far less public attention, results from this study suggest that negative bubbles contribute significantly to price behavior, accounting for more than one-third of total bubble episodes. In general, the size of the bubble (return from bubble extremum to end of bubble) increases as the bubble signal (return from start to bubble extremum) gets larger for both positive and negative bubbles. It appears that during the last half of the sample period, with a couple of exceptions, agricultural futures markets have adjusted faster to stochastic shocks than in the first half of the sample period, resulting in fewer bubbles of shorter length and less over-reaction.
\end{abstract}

Key words: commodity, explosive, futures market, grain, index investment, price impact

JEL Codes: D84, G12, G13, G14, Q13, Q41 


\section{Bubbles in Food Commodity Markets: Four Decades of Evidence}

Food commodity prices have trended upward since 2006 and have experienced several large spikes, the most dramatic in 2007-2008. An acrimonious and world-wide debate has ensued about the nature and cause of the price spikes. Much attention has been directed towards the trading activities of a new type of participant in commodity futures markets — financial index investors. A common assertion (e.g., Masters 2008; 2009) is that unprecedented buying pressure from financial index traders created a series of massive bubbles in agricultural futures prices. However, a number of recent studies fail to find a direct empirical link between index trading and agricultural futures price movements, casting doubt on the view that index trading distorted pricing in these markets (see Irwin and Sanders (2011) for a review of these studies).

The failure to find a link between the positions of a particular group of traders (commodity index traders) and agricultural futures prices does not necessarily rule out the presence of bubble components in prices, particularly during the spikes that have been of such concern to policy-makers. This broader issue of the existence of bubble components in agricultural futures prices has received much less attention to date. Four recent studies have tested for the presence of bubble components in various agricultural prices over the past few years and find mixed results (Gilbert, 2010; Phillips and Yu, 2011; Gutierrez, 2012; Etienne, Irwin, and Garcia, 2012). These studies utilize new bubble tests developed by Phillips, Wu, and Yu (2011), Phillips and Yu (2011), and Phillips, Shi and Yu (2012) which can detect and datestamp bubbles by determining whether prices deviate from a random walk and become mildly explosive. In general, these studies indicate grain futures prices experienced periods of explosiveness with evidence for bubbles in the soft and livestock markets less prevalent. 
While the findings of these recent studies are informative, their test results may be compromised by the use of a series of cash prices or rolling nearby futures price (i.e., constructed using prices until near the maturity date and then switching to the subsequent maturing contract prices). Bobenrieth, Bobenrieth, and Wright (2012) show that in the presence of supply and demand shocks in a rational storage model, cash prices of storable commodities may behave in a bubble-like fashion but the "bubble" is driven entirely by fundamentals. In earlier work, Williams and Wright (1991) show that in the presence of demand and supply shocks cash prices of a storable commodity may contain large spikes that may be similar to the runs detected by the new bubble tests. Wang and Tomek (2005) show that cash prices in general do not follow a random walk and may contain systematic components. Nearby futures prices often behave essentially as cash prices given the short time to contract expiration (Peterson and Tomek, 2005). Thus, explosive periods identified for a cash price or nearby futures price series may be a result of fundamental factors rather than speculative activities.

In addition, there is a technical problem with the use of a series of nearby futures prices for storable commodities. The new bubble tests (e.g., Phillips, Wu, and Yu, 2011) are based on price levels and require the price levels to be differenced before conducting statistical tests. Because nearby futures price series must be "rolled" from one nearby contract to the next before the near contract expires, the price difference on each roll date will be computed across contracts. If a storable market is in contango (near < deferred) the price change will be a relatively large positive value and if a market is in backwardation (near > deferred) the price change will be a relative large negative value. These may not be representative of actual price changes for individual futures contracts on roll dates. The potential for large distortions is especially notable under backwardation since there is no upper bound on how much the nearby can exceed the 
deferred. The end result is that considerable noise may be introduced into bubble tests with the use of a rolling series of nearby futures prices in storable commodity markets.

In this paper, we use the daily prices from individual futures contracts to test whether speculative bubbles exist in agricultural futures markets and identify whether patterns of bubble behavior exist over time. A series of prices from an individual futures contract will behave as a sequence of expected cash prices at maturity and should follow a random walk if one assumes rational expectations and no risk premium or basis risk (Peterson and Tomek, 2005). Deviations from a random walk in the series of prices for individual futures contracts may thus provide more reliable evidence for the presence of a bubble component in prices. We also test for bubbles over very long sample periods. In particular, we test for bubbles in samples of daily prices for 12 agricultural futures markets that begin as far back as 1970 and run through 2011. This allows us to compare the behavior of agricultural futures prices during recent spikes with those during the mid-1970s, the last period of comparable market volatility (Piesse and Thirtle, 2009). The testing algorithm, recently developed by Philips, Shi, and Yu (2012, PSY hereinafter), is based on forward and backward recursively calculated Augmented Dickey-Fuller (ADF) test statistics and is more powerful than previously developed tests because it can detect the existence of multiple explosive periods and find their origination and termination dates. The test procedure is applied to prices from one individual agricultural futures contract per year, typically using the maturity with the highest trading volume.

In addition to the usual formal tests of bubble behavior and time-stamping of bubble periods, we also analyze the characteristics of the bubble periods in terms of length and the size of autoregressive coefficients. Finally, we also conduct an event study to determine whether there is consistent evidence of market prices over-shooting equilibrium during bubble periods. 
Test results demonstrate that all 12 agricultural markets experienced multiple periods of price explosiveness. However, bubble episodes only represent a very small portion of the price behavior for the 42-year period. In addition, most of the bubbles are short-lived, lasting fewer than 20 days. We also find that explosive periods are more common with longer durations in the first half of the sample period, indicating that the most recent bubble episodes may not have been as severe as the mid-1970s episode. Relating bubble magnitudes to coefficient estimates from the SADF test, we find that with the exception of few beginning dates, bubbles have tended to be relatively mild during explosive episodes.

Though receiving far less public attention, results from this study suggest that negative bubbles contribute significantly to price behavior, accounting for more than one-third of total bubble episodes. In general, the size of the bubble (return from bubble extremum to end of bubble) increases as the bubble signal (return from start to bubble extremum) gets larger for both positive and negative bubbles. It appears that during the last half of the sample period, with a couple of exceptions, agricultural futures markets have adjusted faster to stochastic shocks than in the first half of the sample period, resulting in fewer bubbles of shorter length and less overreaction.

\section{Bubble Testing Procedure}

Phillips, Wu, and Yu (2011, PWY hereinafter), Phillips and Yu (2011, PY hereinafter), and Phillips, Shi, and Yu (2012, PSY hereinafter) recently developed a series of recursive bubble testing procedures to detect and date-stamp the exact bubble origination and collapse dates. These procedures were motivated by the observation that the traditional unit root and 
cointegration-based tests proposed by Diba and Grossman (1998) may fail to detect the existence of bubbles when they are periodically collapsing, as demonstrated by Evans (1991).

Specifically, PSY consider the null hypothesis that $P_{t}$ follows a random walk with an asymptotically negligible drift,

$$
P_{t}=d T^{-\eta}+P_{t-1}+\varepsilon_{t}
$$

where $d$ is a constant, $T$ is the sample size, $\eta>1 / 2$, and $\varepsilon_{t} \sim i i d N\left(0, \sigma^{2}\right)$. In the alternative case, there are bubbles in the prices. For illustration, consider when there are two bubble periods with the first one being $B_{1}=\left[\tau_{1 e}, \tau_{1 f}\right]$ and the second $B_{2}=\left[\tau_{2 e}, \tau_{2 f}\right]$, where $\tau_{1 e}, \tau_{1 f}, \tau_{2 e}, \tau_{2 f}$ are the origination and termination dates of each episode, respectively. This data generating process can be represented as:

$$
\begin{aligned}
P_{t}= & P_{t-1} 1\left\{t \in N_{0}\right\}+\delta_{T} P_{t-1} 1\left\{t \in B_{1} \cup B_{2}\right\}+\left(\sum_{k=\tau_{1 f}+1}^{t} \varepsilon_{k}+P_{\tau_{1 f}}^{*}\right) 1 t \in N_{1} \\
& +\left(\sum_{l=\tau_{2 f}+1}^{t} \varepsilon_{k}+P_{\tau_{2 f}}^{*}\right) 1\left\{t \in N_{2}\right\}+\varepsilon_{t} 1\left\{t \in N_{0} \cup B_{1} \cup B_{2}\right\}, \\
& t=1, \ldots, T, \delta_{T}=1+c / T^{\alpha}, c>0, \alpha \in(0,1)
\end{aligned}
$$

where 1 . is the indicator function such that $1\{\}=$.1 when the conditions in the bracket hold and 0 otherwise, $\varepsilon_{k}$ is an iid normally distributed error term, and $N_{0}=\left[1, \tau_{1 e}\right), N_{1}=\left(\tau_{1 f}, \tau_{2 e}\right)$, and $N_{2}=\left(\tau_{2 f}, \tau\right]$ are three non-explosive sub-periods. At the bubble collapse dates $\tau_{1 f}$ and $\tau_{2 f}$, the price reinitializes and jumps to a new level $P_{\tau_{1 f}}^{*}$ and $P_{\tau_{2 f}}^{*}$, respectively. For given values of $c$ and $\alpha$, the parameter $\delta_{T}$, which equals $1+c / T^{\alpha}$, is greater than one in finite samples and approaches one when the sample size $T$ approaches infinity. This defines the mildly-integrated root as specified in Phillips and Magdalinos (2007a). While no general asymptotic inference can be established for purely explosive autoregressive processes as the central limit theory does not 
apply (White 1958; Anderson 1959), the asymptotic behavior of mildly explosive processes is more regular and a least squares regression theory can be established to construct confidence intervals (Phillips and Magdalinos 2007a,b).

Equation (1) implies that to measure the start and end dates of multiple explosive price periods accurately, the testing procedure must first distinguish the explosive behavior of a price series at $\tau_{1 e}$ from its non-explosive behavior at $\tau_{1 e-1}$. Similarly, at $\tau_{1 f}$ the testing procedure must be capable of identifying the transition from an explosive path to a random walk. To achieve this, PSY use a generalized framework with variable window widths in the recursive regressions on which the test procedures are based. Defining the estimation start and end points as $r_{1}$ and $r_{2}$, respectively, their estimation equation becomes:

$$
\Delta P_{t}=\alpha_{r_{1}, r_{2}}+\beta_{r_{1}, r_{2}} P_{t-1}+\sum_{i=1}^{k} \gamma_{r_{1}, r_{2}}^{i} \Delta P_{t-i}+\varepsilon_{t},
$$

where $\Delta P_{t}=P_{t}-P_{t-1}, k$ is the lag order, and $\varepsilon_{t} \sim \operatorname{iid} N\left(0, \sigma_{r_{1}, r_{2}}^{2}\right)$. The ADF $t$ statistic corresponding to this estimation equation is $A D F_{r_{1}, r_{2}}=\frac{\beta_{r_{1}, r_{2}}}{\operatorname{se}\left(\beta_{r_{1}, r_{2}}\right)}$. The varying window size of the regression $r_{w}$ is a function of $r_{1}$ and $r_{2}$ such that $r_{w}=r_{2}-r_{1}+1$. Defining $r_{w_{0}}$ as the minimum window size required to estimate equation (2) and a fixed ending point $r_{2}$, the starting point $r_{1}$ can vary between the first observation to observation $r_{2}-r_{w_{0}}+1$. By varying the starting point $r_{1}$ there are $\left[r_{2}-r_{w_{0}}+1\right]$ ADF t statistics for any fixed ending point $r_{2}$. Let $S A D F_{r_{2}}$ be the maximum of those $\left[r_{2}-r_{w_{0}}+1\right]$ ADF t statistics such that $S A D F_{r_{2}}=$ $\operatorname{Sup}_{r_{1} \in\left[1, r_{2}-r_{w_{0}}+1\right]} A D F_{r_{1}, r_{2}} \cdot{ }^{1}$ Now allow the ending point $r_{2}$ to vary between $r_{w_{0}}$ and $T$, the last data point included in the estimation; we then obtain $\left[T-r_{w_{0}}+1\right] S A D F_{r_{2}}$ statistics each 
obtained from a backward-expanding window. Denote the maximum of $S A D F_{r_{2}}$ as $G S A D F_{\tau}^{r_{w_{0}}}$ such that:

$$
G S A D F_{\tau}^{r_{w_{0}}}=\sup _{r_{2} \in\left[r_{w_{0}}, \tau\right]}\left\{\sup _{r_{1} \in\left[1, r_{2}-r_{w_{0}}+1\right]}\left(A D F_{r_{1}, r_{2}}\right)\right\}
$$

Then, the existence of an explosive period is confirmed if $G S A D F_{T}^{r_{w_{0}}}>c v_{T, r_{w_{0}}}^{\rho}$, where $c v_{T, r_{w_{0}}}^{\rho}$ is the $100 \rho \%$ critical values based on $T$ observations and a minimum window size $r_{w_{0}}$. The GSADF test statistic is essentially a rolling window ADF test with a double-sup selection criterion, in which both the starting and ending points of the estimation vary. In various simulations, PSY show that the test possesses good discriminatory power in detecting multiple periods of price explosiveness over entire sample periods.

To locate the specific explosive periods, the backward $S A D F_{r_{2}}$ test statistics are compared to their respective critical values obtained from Monte Carlo simulations. The estimated origination and ending dates of the first explosive episode are specified as:

$$
\begin{aligned}
& \widetilde{r_{1 e}}=i n f_{r_{2} \in\left[r_{w_{0}}, n\right]}\left\{r_{2}: S A D F_{r_{2}}>c v_{r_{2}}^{\rho}\right\} \text { and } \\
& \widetilde{r_{1 f}}=i n f_{r_{2} \in\left[\widetilde{r_{1 e}}+h, n\right]}\left\{r_{2}: S A D F_{r_{2}}<c v_{r_{2}}^{\rho}\right\},
\end{aligned}
$$

where $c v_{r_{2}}^{\rho}$ is the $100 \rho$ critical values of the backward-expanding SADF statistic based on $r_{2}$ observations. In essence, the origination date is defined as the first date that the sup test statistics $S A D F_{r_{2}}$ exceeds the corresponding critical value, and it terminates as soon as it falls below the critical value. The estimated origination and collapse dates of the second explosive episode can be defined in a similar way. PSY obtained the asymptotic distribution of the backwardexpanding SADF test statistic and proved that under a variety of scenarios, the SADF test can consistently detect the start and end dates of explosive periods. ${ }^{2}$ One important advantage of the PSY testing procedure is that it allows testing the bubble origination and termination dates on a 
real-time basis, which may be of considerable value to policymakers who want to reduce price variability and curb food crises in developing countries.

Earlier work by PWY and PY are also based on recursively calculated ADF statistics, while in the PWY, the starting point of each regression $r_{1}$ is set to the first observation of the sample, and in PY the starting point is selected based on the BIC value. Homm and Breitung (2011) show that in various simulations the PWY procedure performs satisfactorily against other recursive procedures and is particularly effective as a real-time detection algorithm for explosive market behavior. However, in either case, the regression only involves a forward recursive window given that $r_{1}$ is the same for every test statistic. While the PWY and PY procedures can consistently detect the origination and termination dates of the first bubble period ( $B_{1}$ in equation (4)), it is not difficult to understand that these two procedures may be severely biased when estimating the timespans of the second bubble period $B_{2}$, especially when $B_{1}$ is longer than $B_{2}$. Since PWY and PY procedures use a single starting point for the entire testing process, signals from the first explosive episode may be mixed with the second one. Often the downward bias from the first explosive sub-period can contaminate the ability of successful detection of the following explosive period. PSY show that when the alternative hypothesis contains multiple bubbles, their testing procedure consistently outperforms the PWY procedure.

Several studies have applied the PWY and PY procedures to various agricultural markets and find mixed results. Gilbert (2010) examines seven commodity futures markets and only finds explosive periods in copper and soybean prices. By contrast, Gutierrez (2012) finds evidence of explosiveness in wheat, corn and rough rice prices in 2007-2008, but not in soybean prices. Phillips and Yu (2011) find no explosive periods in deflated coffee, cotton, cocoa, sugar, and feeder cattle cash prices. Only Etienne, Irwin, and Garcia (2012) have applied the PSY 
procedure to nearby grain futures prices and find significant evidence of explosive periods in all four markets examined.

\section{Futures Price Data}

As noted earlier, explosive periods identified by previous work that relies on cash prices (Phillips and Yu 2011) or rolling nearby futures prices (Gilbert 2010; Gutierrez, 2012; Etienne, Garcia, Irwin 2012), may be driven by fundamental demand and supply factors rather than an explosive bubble component. In contrast, futures prices derived from an individual contract should behave as a random walk under fairly general conditions. Specifically, the futures price at time $t$ for a contract maturing at $T$ is the expected cash price of a certain commodity at time $T$ conditional on the information available at time $t$ (e.g., Fama and French, 1987; Tomek, 1997), or $F_{t}^{T}=$ $E_{t}\left(P_{T} \mid I_{t}\right)$, assuming rational expectations, no risk premium, and no basis risk. Hence, prices from individual futures contracts will behave approximately as a sequence of expected cash prices at maturity and follow a random walk (Peterson and Tomek, 2005). Deviations from a random walk in the series of prices for individual futures contracts may thus provide a "cleaner" test of bubble components in agricultural futures prices. ${ }^{3}$

Two issues are presented when using individual contract prices for bubble tests. First, an important characteristic of futures prices for an individual contract is that price variance increases as contract maturity approaches (Samuelson, 1965). This hypothesis has been widelytested empirically, and in general, studies have agreed that the "time-to-maturity" effect does exist (e.g. Anderson 1985). In addition, prices and price variability for annual crops are affected by the seasonality of underlying markets. This implies that, holding other factors constant, prices should be more volatile in the growing season as more information about expected yield 
arrives during this period (Tomek and Peterson, 2001). Fortunately, the PSY testing approach is likely to account for either of these situations, as the forward and backward recursive procedure ensures that for different regressions, the error terms are allowed to have different variances. ${ }^{4}$

We consider the 12 agricultural futures contracts included in the Commodity Futures Trading Commission (CFTC) Supplemental Commitment of Traders (SCOT) report. Specifically, these include five grain futures (Chicago Board of Trade (CBOT) corn, soybeans, soybean oil and wheat; Kansas City Board of Trade (KCBOT) wheat), three livestock futures (Chicago Mercantile Exchange (CME) feeder cattle, live cattle, and lean hogs), and four softs futures (Intercontinental Commodity Exchange (ICE) cocoa, coffee, cotton, and sugar). For each commodity, we examine one contract each year, typically the contract with the highest trading volume, i.e., the December contract for corn, soybean oil, lean hog, live cattle, cocoa, coffee, and cotton futures, the November contract for soybean and feeder cattle futures, the October contract for sugar futures, and the July contract for the two wheat futures series. We use log daily prices and samples are extended as far back as 1970 and all run through 2011. This results in 42 contracts (or individual price sequences) for each commodity. The only exceptions are feeder cattle and coffee futures, whose data were not available until 1972 and 1973, respectively. As a result, 40 contracts are examined for feeder cattle and 39 for coffee futures.

Given that trading for contracts often extends more than a year before expiration, the price data needs to be aligned in order to avoid periods of potentially overlapping bubbles. For instance, futures quotes on 6/1/2010 are available for both December 2010 and December 2011 corn contracts. If both prices pass the PSY test then this date will be considered explosive in both price sequences. To avoid this, we let each price sequence start 13 months before the contract expiration dates and end on the last trading day of the month before the contract expires. 
These two rules result in 13-month sample period for each contract. For instance, the sample for December 2011 corn contract includes observations from 11/1/2010 to 11/30/2011, and for December 2010 corn contracts it starts on 11/1/2009 and ends on 11/30/2010. Since the first 20 observations are used as the initial start-up sample for the PSY procedure $\left(r_{w_{0}}\right.$ in the testing procedure, or the minimum window size), bubbles in the December 2011 contract will fall within 12/1/2010 to 11/30/2011. For the December 2010 contract, the feasible range of bubble is from $12 / 1 / 2009$ to $11 / 30 / 2010$. Constructing data in this way ensures that all non-overlapping bubble periods, if they exist, can be detected in the individual contract sequences.

PSY show that their test has good power properties for samples of 200 or more monthly observations. Specifically, simulations show that the GSADF test has a statistical power of 0.833 (0.977) for a sample size of 200 (400). Each of the 42 yearly sequences for all commodities except coffee and feeder cattle have daily sample sizes ranging generally between 240 and 260 observations. PSY’s analysis suggests samples of this size should provide good power to detect bubble periods if they exist. Finally, since the time period for each futures price sequence is 13 months or less there is no need to deflate the data, as the consumer price index (CPI) is unlikely to vary much over each 13 month period.

\section{Test Results}

As a first step in determining the existence of explosive periods and locating their exact origination and termination dates, the lag order in the estimation equation (5) must be specified. Phillips and Yu (2009) argue that the asymptotic distributions of the test statistics remain the same when a low lag order is used, so PY (2011) used a lag order of zero when conducting the forward recursive analysis with initialization of the first observation. PSY further demonstrate 
that adding lag orders can potentially bias the estimation results and recommend obtaining the ADF test statistics with a lag order of zero. We thus employ the testing strategy recommended by PSY and set the lag order to zero ( $k=0$ in equation (5)). The initial start-up sample for the generalized forward recursive analysis contains 20 observations, or roughly one month. The minimum window size is 20 observations as well. ${ }^{5}$ As an example, consider obtaining the SADF test statistics for a fixed ending data point $21\left(r_{2}=21\right)$, two regressions are estimated where the first starts with observation $1\left(r_{1}=1\right)$ and the second with observation $2\left(r_{1}=2\right) . S A D F_{21}$ is then set to the larger ADF $t$ statistics calculated from those two regressions.

Also note in equations (6) and (7) when defining the end dates of the explosive periods, the price explosiveness needs to last at least $h$ periods to be considered economically meaningful. PWY (2011) suggest the minimum length of the explosive period to be $\log (T)$, giving a minimum length of 5-6 days for the data considered in this study. In a competitive futures market it is reasonable to assume that information is reflected quickly, even if not instantaneously, in futures prices and market participants react rapidly to any new information. Hence, any price movement away from prices based on fundamentals is likely to be short-lived (Streator and Tomek, 1993; Smith, 2012). This helps to justify a relatively short 5day rule for defining bubble periods. As a robustness check, we also consider a minimum bubble length of 10 days (or two weeks), which is the criterion adopted in Gilbert (2010).

For illustration, the PSY GSADF and SADF testing procedure is presented in figure 1, where we detect and date-stamp bubbles in the 2008 contract prices of soybean oil, KC wheat, and sugar. The GSADF statistic (maximum of SADF) of 2.73 is attained on 3/3/2008 for the December 2008 soybean oil contract. As it exceeds the 95\% critical value of 2.57, the price 
series is said to contain a bubble component. The date-stamping results are found by comparing the SADF statistic with the $95 \%$ critical value sequences.

One assumption we implicitly make under the random walk null is that individual futures contract prices do not contain a risk premium, or $F_{t}^{T}=F_{t-1}^{T}+\varepsilon_{t}$. It may be possible that short hedgers reward long speculators with a risk premium for bearing price risk, as first argued by Keynes (1930) and Hicks (1939). If this is true futures prices before the maturity date are biased downward in order to embed the risk payment. Such a data generating process including a drift term is $F_{t}^{T}=d T^{-\eta}+F_{t-1}^{T}+\varepsilon_{t}$, as shown in equation (3). Though the risk premium assumption remains rather controversial and empirical evidence provides mixed results (e.g., Carter, 1999; Garcia and Leuthold, 2004), it is true that when the drift term is large and the variance of the random component is small, the drift/risk premium term can dominate periods of price spikes, similar to the explosive behavior shown in equation (2). Phillips, Shi, and Yu (2011) show that when the drift term is negligible, or $\eta>1 / 2$ for a fixed constant $d$, run-ups generated by the explosive behavior can be consistently distinguished from a unit root process. They also propose a consistent procedure to estimate $\eta$, which we apply to our current data and find that its value ranges from 0.58 to 2.08 for the individual futures contract series. Hence, the risk premium component is negligible for the data considered in this study. The existence of a large risk premium term in individual contract prices may also be ruled out by economic theory. Suppose the drift term equals 1 , or $\eta=0$ and $d=1$. Then the futures market presents a constant growth rate of $100 \%$, which is rather unrealistic. ${ }^{6}$ Overall, results from the PSY procedure applied to our current dataset indicate that test results are unlikely to be materially affected by a risk premium component in futures prices. 
Complete test results are discussed in the following subsections. To facilitate discussion, the 42-year sample periods are divided into two sub-periods, 1970-1990 and 1991-2011. For convenience, they are referred to as period 1 and period 2, respectively. Table 1 summarizes the GSADF bubble testing results when applied to the 12 commodities. Each cell reports whether the GSADF test statistic is significant at the 95\% significance level for individual contract prices each year for each commodity. As can be seen, most of the commodities experienced bubbles throughout the sample period, with a larger portion of individual contract series found to contain bubbles, particularly in softs and livestock futures. Of the 499 sequences considered for each dataset, 141 series show a significant bubble component for individual contracts.

Several general patterns emerge from these tests results. For instance, prices in the early sample period are more likely to experience bubbles, with $35 \%$ more price sequences containing bubbles in period 1 than period 2. This conclusion holds for the two sub-periods with particularly volatile prices, 1971-1976 and 2006-2011. In addition, wheat, cocoa, and cotton tend to experience between $20 \%$ to $40 \%$ fewer bubbles by number of contracts than other commodities.

As an aside, if we run the right-tailed ADF test on each price sequence without the recursive procedure as in PSY, only 41 individual contract price series are found to be explosive at the 95\% significance level. The sharp contrast between the results from traditional right-tailed ADF and GSADF tests underline the importance of adopting a recursive procedure when bubbles are periodically collapsing, in which case the price sequences may behave like a unit root or even stationary processes. 


\section{SADF Date-stamping Results}

Results from the SADF tests are presented in tables 2 and 3 for a minimum bubble length of 5 and 10 days, respectively. The price sequences experiencing bubbles implied from tables 2 and 3 may not exactly match the results presented in table 1 for a number of reasons. First, due to the rules we used to construct price series, the "year" represented in table 1 is not the actual calendar year, but rather the year when the contract expires. For instance, the bubble testing range for wheat in 1995 begins around July 1994 and ends in June 1995. This is the definition used in table 1 . However in tables 2 and 3, the specific date-stamped bubbles are aligned by the actual calendar year. Thus the explosive episodes in calendar year 1995 in tables 2 and 3 may have occurred in the July 1995 or July 1996 contracts of wheat in table 1. Second, the GSADF test statistic is significant as long as it exceeds the critical value (table 1), whereas the date-stamping procedure employed in tables 2 and 3 requires that the SADF test statistic exceeds the critical values for 5 or 10 consecutive days. Third, since the GSADF statistic represents the maximum value of the SADF statistic and the former has a much higher critical value, it occurs sometimes when the SADF statistic exceeds its corresponding critical values while the GSADF statistic fails to do so.

The specific date-stamping results based on the SADF test varies substantially with the minimum bubble length ( $h$ in equation (7)) used. On average, about 56\% more days experiencing bubbles are identified using a minimum bubble length of 5 compared to 10 for the 42-year period. The increase in feeder cattle and live cattle futures is especially significant, both rising $84 \%$ from 238 to 438 days and from 194 to 357 days when using $h=5$, respectively. The discrepancies in the date-stamping results with different $h$ presented in tables 2 and 3 highlight the importance of specifying different levels of minimum bubble length in order to obtain a more 
complete picture of the bubble occurrence when date-stamping for price explosiveness in commodity futures markets.

One important pattern arise from tables 2 and 3 is bubbles tended to occurr less frequently in period 2 compared to period 1. On average, the percentage of days experiencing bubbles for all 12 markets decreased from 5.1\% during period 1 to $4.1 \%$ in period 2, using a minimum bubble length of 5 days. Results are proportionally similar when $h=10$, as the bubble frequency decreased from 3.6\% to $2.5 \%$ from period 1 to period 2. Marketwise, it appears that with few exceptions, bubbles occurred much more frequently during the earlier part of the sample period for grains and softs. For instance, bubbles occurred in $10.4 \%$ of the sample during period 1 and dropped to 2.8\% during period 2 in coffee prices, when the minimum bubble length is 5 days. For livestock, however, bubbles occurred slightly more often in period 2, though the differences in total number of days are rather small.

Figure 2 presents the 10 years with the highest and lowest percentage of days experiencing bubbles across all 12 markets. Not surprisingly, 1973 and 2008 are the two years possessing highest bubble frequencies, with about $14 \%$ and $13 \%$ of the days falling in the bubble periods for $h=5$, respectively. For the remaining years, the bubble frequencies are generally less than 8\%. Comparing periods 1 and 2, though each possesses 5 of the 10 highest bubble frequency years, most years with the lowest bubble frequencies occurred in period 2. In addition, 5 of the top 10 years with the highest bubble frequencies occurred in 1971-1976 and 2006-2011, two sub-periods when the prices were extremely volatile.

Overall, it is important to note that bubble episodes only appear to represent a small portion of the price behavior for the entire sample considered in this study. With very few exceptions, the percentage of trading days with explosive prices is less than $5 \%$ over the 42 -year 
period for the 12 commodities examined. In addition, fewer bubbles are found in most commodities during the latest sub-period, as compared to the '70s and '80s. Although agricultural futures markets exhibited occasional explosive periods throughout the last four decades, responsiveness to information appears to have improved over time with the move into a new era with skyrocketing volume and open interest in futures markets, new participants and new trading technologies in futures markets, and the "financialization" of commodity markets (Irwin and Sanders 2012). The resulting increased market liquidity appears to have reduced the frequency of bubbles, despite the high prices and volatilities that have occurred since 2006.

\section{Bubble Characteristics}

The preceding discussion focuses only on the frequency of bubbles over the sample period, instead of the specific patterns of each bubble episode. Given the existence of bubbles, policymakers are surely interested in knowing how long the bubble episodes tend to last and how fast the bubble grows. Table 4 summarizes the descriptive statistics of bubble length by commodity during each 21-year sub-period, while figure 3 shows the frequency distributions of bubble length. Several prominent patterns emerge. First, the distribution of bubble length is highly right-skewed. It appears that most of the bubbles are short-lived, with over $80 \%$ and $65 \%$ of the bubble episodes lasting less than 20 days for $h=5$ and $h=10$, respectively. Second, bubbles in grain and softs futures tend to last longer than in livestock markets, indicating that storability might have played a role in determining the bubble duration. This difference, however, is more significant in period 1 than in period 2. Third, bubbles tend to last slightly shorter with smaller variations in the period 2 compared to period 1 . For instance, the average 
bubble duration in period $1(h=5)$ is 12 days, dropping to 11 days in period 2. This difference in length is statistically significant at the $10 \%$ level.

One way to measure the bubble growth rate is to examine how much prices deviated from a random walk, that is, to obtain $\delta_{T}$ in equation (4), or $\beta_{r_{1}, r_{2}}$ in the regression equation (5) when a significant SADF value is achieved for a fixed ending point $r_{2} \cdot{ }^{7}$ A potential misconception is to associate the SADF test statistics obtained from regression equation (5) with the bubble magnitude. For instance, consider the backward SADF sequences for December 1973 corn futures, as shown in Figure 4(a). It can be seen that there were four episodes when the SADF statistics exceeded the critical values, but only two lasted more than 5 days and were determined to correspond to bubble periods (shaded areas in the figure): 5/23/1973 - 6/13/1973 and 7/20/1973 - 8/22/1973. It is tempting to measure the bubble significance by measuring the magnitude of SADF statistics, which may lead to the conclusion that bubbles have been most pronounced when the SADF statistics are the largest. However, consider the episode 7/20/1973 - 8/22/1973 when prices were highest during the contract life-span. Based on the SADF statistics, bubbles appear most significant around 8/14/1973, coinciding with the date when prices reached their peak. However, an examination of the regression coefficient $\beta_{r_{1}, r_{2}}$ in figure 1(b) shows that prices during this period only deviated from a random walk slightly, with the average $\beta_{r_{1}, r_{2}}$ being 0.0128, corresponding to an AR coefficient of 1.0128. The large SADF statistics observed during this period can be attributed to the small variance of data used in the backward recursive process when SADF is achieved, rather than a large regression coefficient.

Of course, the AR coefficient may sometimes possess a large magnitude, resulting in an SADF statistic exceeding critical values. Consider 12/4/1972 in figure 1 when $\beta_{r_{1}, r_{2}}$ is around 0.20 (AR coefficient of 1.20). The SADF statistic on this date is larger than the 95\% critical 
value, but this large regression coefficient only lasted for two days before falling back and becoming negative. This period is thus too short to be considered a bubble. In other words, bubbles, if they are pronounced, may have only lasted a very short period of time. A similar pattern is observed for the two other short periods in which the SADF statistic exceeds the critical values (one in August and the other in November 1973).

To reflect the range of results we present eight other instances when long bubble periods are detected by the PSY procedure, as shown in figure 5. Most of these bubbles lasted more than 40 days, or roughly two months. In the figure we see two negative bubbles with prices trending downward during the bubble period, one in December 1985 corn contracts (figure 5(b)), and the other in December 1994 lean hog contracts (figure 5(h)). In 1985, the December 1985 corn contract price decreased from their peak of over $\$ 2.80 /$ bu. in November 1984 to a low of \$2.15/bu. in September 1985. In 1994, the hog market collapsed, leading to a sharp decrease in hog prices and forcing out many small producers. Notice in figure 5 that the estimated regression coefficient never exceeded 0.025 for the bubble episode in December 1985 corn contract. For December 1994 lean hog contracts, the average coefficient estimates is 0.008 . The remaining six cases in figure 5 consider positive bubbles in December 1983 soybean oil, November 1976 soybeans, December 1973 cocoa, December 1994 coffee, November 2010 feeder cattle, and December 2003 live cattle contracts. Similar patterns are seen in these contracts, where the regression coefficient tends to be of low magnitude throughout the explosive periods with the exception of a few beginning dates. While the degree to which a price sequence deviates from a random walk may not completely reveal how large the bubble has been, it certainly indicates that from a statistical perspective, most bubble periods in commodity futures markets over the past 42 years have been relatively mild. 


\section{Event Study of Returns during Bubbles}

If bubbles indeed existed in the market, how much may have the observed prices been overvalued compared to fundamentals? Answering this question is particularly challenging for commodities given that their fundamental values are often hard to measure. Gheit (2008) argues that the price of crude oil exceeding \$135 per barrel in 2008 is unwarranted, and believing that the fundamental price was below $\$ 60$ per barrel. Using a Quantum index, Gilbert (2010) finds that the maximum price impact of financial index traders ranges from $9.6 \%$ to $17.1 \%$ for grains, metals, and energy products. While interesting, these studies can often be criticized for issues related to correctly specifying fundamental values.

In this study, we avoid directly estimating fundamental values and infer bubble size indirectly from price changes during explosive periods. We have assumed that prices follow a random walk when absent of bubbles, which in theory should correctly reflect the fundamental demand and supply relationship. On the date in when a bubble is identified by the PSY procedure the explosive component becomes significant and price can no longer be considered equal to fundamental value. In a competitive futures market we assume that traders will then actively seek to correct the unjustified price movement until eventually a new equilibrium is reached. The price on the date when an explosive period comes to an end may thus be viewed as the new equilibrium price - the price that correctly reflects the new fundamental supply and demand conditions after the market appropriately allocates all the available resources among market participants.

Recognizing that prices are not always upward trending when bubbles occur (e.g. figures 5(b) and 5(h)), we first divide explosive periods into two groups: positive and negative bubbles. Positive bubbles are defined as when the average price during the explosive period is greater 
than the initial price when the explosive period starts, and vice versa. To calculate the bubble size, we consider prices at origination, peak (trough), and conclusion dates for each bubble period, resulting in two indicators: returns from start to peak (trough) and returns from peak (trough) to end. Under this framework, the latter indicator measures how much price has corrected before returning to a random walk process. Returns from peak (trough) to end thus provide a measurement of how much the price is overvalued compared to fundamentals.

We focus our discussion on bubbles that last for at least 10 days. These are the bubble episodes that policymakers would be more interested in analyzing given that the impact of a bubble is likely to increase with its length. Table 7 presents the average cumulative daily returns during each bubble episodes in periods 1 and 2 for both positive and negative bubbles. The left panel of table 7 presents the average returns of positive bubbles. As can be seen, the signal of price distortion is often weaker in period 2 compared to period 1 ( $21 \%$ vs. $16 \%)$. On average across all 12 markets, price is overvalued 4\% in period 1 and 3\% in period 2, both statistically significant from zero. The most significant price change occurred in cotton futures, as the percentage of unwarranted price increase gets as large as $11 \%$ in cotton futures in period 2 . With few exceptions, the price of most commodities often correct beyond $3 \%$ in period 1 . The magnitude of price correction for markets other than cotton and sugar are rather small in period 2, often less than $2 \%$.

As shown in the right pane of table 7, a substantial portion of the bubbles are negative accounting for $36 \%$ and $41 \%$ of the bubbles across all commodities for periods 1 and 2, respectively. It appears that negative bubbles occurred most often in softs during period 1, and livestock products during period 2, with each of them accounting for about $50 \%$ of the total negative bubbles during each respective sub-period. For both periods, price on average drops 
around $11 \%$ from start to trough during a negative bubble episode, then corrects about $3 \%$ by the time it returns back to a random walk. This process typically lasts from 3 to 4 weeks. Given the frequent occurrence of negative bubbles, it is surprising to note that this category of bubbles has been largely ignored by the literature. While prolific public discussion has been directed to positive bubbles when prices rise above its fundamental values, their negative counterparts certainly deserve a comparable amount of attention.

A logical expectation is that during a bubble episode the larger the bubble signal the larger the price correction would be. It would be then useful to formally establish a statistical relationship between those two indicators. This is demonstrated in figure 7, which shows a scatterplot of the return from start to peak (trough) and return from peak (trough) to end for each period, along with a regression line between these two indicators. The positive relationship is confirmed for both positive and negative bubbles. While the magnitudes of the slope for negative bubbles are quite close during both periods, it is about $1 / 3$ larger for positive bubbles in period 2 than in period 1. It appears that given equally-sized positive and negative bubble signals, the market tends to correct itself in a faster rate when the price is overvalued than undervalued. In addition, period 2 market dynamics are more responsive, correcting much faster for a given increase in bubble signal. The arrival of new traders in recent years, coupled with a dramatic increase in trading volumes and open interests, has increased market liquidity, apparently forcing the market to correct faster to distorted price signals.

Care must be taken not to imply that the relationships in figure 7 can be used as a practical trading rule. For instance, one might be tempted to buy at the beginning of a positive bubble, and sell when the bubble ends. The regression estimates suggest that during period 2 a $1 \%$ increase in the price change from start to peak will be following by a $0.32 \%$ decrease when the 
positive bubble collapses. However, this trading strategy is unlikely to be profitable in practice. First, the regression estimates are based on the ex-post 10-business day rule when determining the bubble episode. In real-time, one cannot foresee how long the bubble will last. The false signals generated by the data are likely to cancel out any potential profit gained from real bubbles. Similarly, the distinction made between positive and negative bubbles are also based on an ex-post rule, though in this case the bubble category may be recognized from the price trend during the first few days of the bubble episode. Third, one may argue that once a positive bubble has been identified, a profit can be established by taking a long position at day 11, then taking the opposite position when the bubble collapses. This is also unlikely to be profitable given that most of the bubbles are short-lived.

Finally, given the many parallels that exist between price movements in 1971-1976 versus 2006-2011, we compare the sizes of bubbles that occurred during these periods that are of particular concern to both the public and policy-makers, as shown in the table 8. Both periods represent more than $35 \%$ of the positive bubbles in their respective sub-sample periods. It is surprising that even with such rapid price increases during these two periods there exists a significant portion of negative bubbles (17\% and 32\%, respectively). Contrary to the argument that commodity prices are now more prone to bubbles than three decades ago, more bubbles occurred during 1971-1976 than during 2006-2011 (42 vs. 28 for positive bubbles). In addition, bubbles during 1971-1976 tend to be more pronounced and last longer. While the average size of bubble signal and the average percentage of price correction during 2006-2011 is almost identical to the mean values during period 2, these two indicators are more than $10 \%$ larger than the mean values during period 1 . 
A close examination of table 8 also suggests that the size of the bubble signal and overvaluation percentage would have been much lower if the bubble in the December 2010 cotton contract is excluded. Here the cotton price increased $69 \%$ from start to peak, then dropped 19\% when the bubble collapsed. A plot of the cotton price behavior during this period, as well as the SADF date-stamping results and autoregressive coefficient estimates, are presented in figure 8. Notice that the bubble originated on $8 / 2 / 2010$ when the price is 79.34 (or $\log$ (price) $=4.37$ ), gradually reaching its peak on $11 / 9 / 2010$ at 151.23 (or $\log ($ price $)=5.02$ ). When the bubble comes to an end on $11 / 22 / 2010$, the price dropped to 121.9 (or $\log ($ price $)=4.80$ ). The estimated regression coefficients suggest that, although the degree to which the price process deviated from a random walk was quite mild throughout the bubble period, the price nearly doubled from the bubble origination date to its peak.

\section{Conclusions}

In this paper, we find all 12 of the agricultural commodities examined have experienced multiple bubbles between 1970 and 2011. These results were obtained by applying the multiple bubble testing procedure of Phillips, Shi, and Yu (2012) to daily price sequences for individual futures contracts. Unlike previous studies that only use nearby futures prices or cash prices, which may present explosive behavior due to changes in fundamentals, results generated from prices for an individual contract are much cleaner. Applying the SADF date-stamping tests to these 12 commodities, we find that results are somewhat sensitive to the minimum bubble length used. Overall, 50\% more bubbles are identified when using a minimum bubble length of 5 days compared to 10 days. However, even with the 5-day rule, bubbles only represents less than $5 \%$ of the price behavior for the 42-year period in most commodities. We also find fewer bubbles 
occurred between 1991 and 2011 compared to 1970-1990. An examination of the bubble length suggests that most of the bubbles are short-lived, with over $80 \%$ and $65 \%$ of the bubble episodes lasting less than 20 days for a minimum window length of 5 and 10 days, respectively. It also appears that the duration of bubbles between 1991 and 2011 bubbles is slightly less, compared to 1970-1990. Relating bubble magnitudes and growth rate to coefficient estimates from the SADF test, we find that with only a few exceptions, bubbles may have been mild throughout the explosive period.

We define a bubble as "positive” if the average price during a given bubble is larger than the price at the bubble start date, and "negative" otherwise. Although more than one third of the bubbles detected by the SADF procedure are negative, it is surprising that little attention has been paid to negative bubbles in the literature. We define the price change from start to peak (trough) as the size of bubble signal, and the price change from peak (trough) to end as the true bubble size that the market has attempted to correct. In general, there is a positive correlation between bubble signal and true bubble size. Additionally, it appears that during the latter sample period, the market has been more responsive to bubble signals, adjusting to new equilibrium faster than the earlier sample period.

Though we find bubbles throughout the 42-year period, their high frequency and magnitude in 1971-1976 and 2006-2011 are certainly of most concern. Interestingly, both positive and negative bubbles tend to be shorter in duration and with smaller sizes in 2006-2011 compared to 1971-1976. In addition, more bubbles occurred during the earlier period. This pattern holds for almost all the grain, livestock, and softs futures examined.

Our analysis indicates that commodity futures markets are now less prone to bubbles than three decades ago, despite the recent price spikes and heightened price volatility. Relating this to 
Master's argument that financial index investors were responsible for unprecedented bubbles in commodity futures prices, it is evident that bubbles existed long before these investors arrived on the scene and the process of commodity market financialization started. Indeed, results for nearly all markets show that on statistical grounds, prices during 2006-2011 were less susceptible to bubbles compared to 1971-1976 when financial index investors were not yet in existence. While commodity futures markets are not perfectly efficient, the arrival of new market participants, coupled with a dramatic increase of trading volumes and open interest, as well as the adoption of new trading technologies, have apparently increased the market liquidity and resulted in improved responsiveness to information.

Given the persistence of bubble phenomena in futures markets, it is clear that additional research is needed to identify their source(s). They may be caused by fads, herding behavior, feedback trading, or other noise traders that have long plagued futures market. Recent empirical evidence does suggest that herding behavior exists in futures markets among hedge funds and floor market participants (Boyd et al. 2010). A related research focus might investigate, for example, the behavior of commercial, non-commercial, and managed money traders, carefully analyzing their interactions during explosive periods to develop a more comprehensive understanding of the causes of bubbles in futures markets. 


\section{References}

Anderson, R.W. “Some Determinants of the Volatility of Futures Prices.” Journal of Futures Markets 5 (1985):331-48.

Anderson, T.W. “On Asymptotic Distributions of Estimates of Parameters of Stochastic Difference Equations.” The Annals of Mathematical Statistics 30 (1959):676-687.

Bobenrieth, E.S.A., J.R.A. Bobenrieth, \& B.D. Wright. "Bubble Trouble? Rational Storage, Mean Reversion and Runs in Commodity Prices”, Paper presented at NBER Conference on “The Economics of Food Price Volatility,” Seattle, WA, August 15-16, 2012.

Bos, J.W.B., and M. Molen. “A Bitter Brew? Futures Speculation and Commodity Prices.” Working Paper, Maastricht Research School of Economics of Technology and Organization, 2012.

Boyd, N. E., B. Buyuksahin, J.H. Harris, and M. S. Haigh. “The Prevalence, Sources, and Effects of Herding”, Working Paper. 2012. Available at SSRN: http://ssrn.com/abstract=1359251 or http://dx.doi.org/10.2139/ssrn.1359251

Carter, C.A. “Commodity Futures Markets: a Survey.” Australian Journal of Agricultural and Resource Economics 43 (1999):209-47.

De Long, J.B.d., A. Shleifer, L.H. Summers, and R.J. Waldmann. "Positive Feedback Investment Strategies and Destabilizing Rational Speculation.” The Journal of Finance 45 (1990):379-95.

Diba, B.T., and H.I. Grossman. “Explosive Rational Bubbles in Stock Prices?” The American Economic Review78 (1988):520-30. 
Etienne, X.L., S.H. Irwin, and P. Garcia. "Price Explosiveness and Index Trader Behavior in the Corn, Soybean, and Wheat Futures Markets.” Proceedings of the NCCC134 Conference on Applied Commodity Price Analysis, Forecasting, and Market Risk Management. April 16-17, 2012 (http://www.farmdoc.illinois.edu/nccc134/conf_2012/pdf/confp0312.pdf)

Evans, G.W. "Pitfalls in Testing for Explosive Bubbles in Asset Prices.” The American Economic Review 81 (1991):922-30.

Fama, E.F., and K.R. French. “Commodity Futures Prices: Some Evidence on Forecast Power, Premiums, and the Theory of Storage.” The Journal of Business 60 (1987):55-73.

Fattouh, B., L. Kilian, and L. Mahadeva. “The Role of Speculation in Oil Markets: What Have We Learned So Far?” Working Paper, Oxford Institute for Energy Studies, 2012.

Gheit, F. “Testimony before the Subcommittee on Oversight and Investigations of the Committee on Energy and Commerce, U.S. House of Representatives.’’ Available online: http://energycommerce.house.gov/cmte_mtgs/110-oi-hrg.062308.Gheit-testimony.pdf

Gilbert, C.L. “Speculative Influences on Commodity Futures Prices 2006-2008.” United Nations Conference on Trade and Development Discussion Paper No.197, 2010.

Gutierrez, L. “Speculative bubbles in Agricultural Commodity Markets.” European Review of Agricultural Economics 39 (2012): 1-22.

Hicks, J.R. Value and Capital. Oxford, UK: Oxford University Press, 1939.

Homm, U., and J. Breitung. “Testing for Speculative Bubbles in Stock Markets: A Comparison of Alternative Methods.” Journal of Financial Econometrics 10 (2012):198-231.

Irwin, S.H., and D.R. Sanders. “Index Funds, Financialization, and Commodity Futures Markets.” Applied Economic Perspectives and Policy 33 (2011):1-31. 
Irwin, Scott H., and Dwight R. Sanders. "Financialization and Structural Change in Commodity Futures Markets.” Journal of Agricultural and Applied Economics 44(2012):371-396.

Keynes, J.M. Treatise on money: Pure theory of money. London, UK: Macmillan, 1930.

Masters, M.W. "Testimony before the Committee on Homeland Security and Governmental Affairs, United States Senate.” May 20, 2008. (http://hsgac.senate.gov/public/_files/052008Masters.pdf).

Masters, M.W. “Testimony before the Commodity Futures Trading Commission.” August 5, 2009.

(http://www.cftc.gov/ucm/groups/public/@newsroom/documents/file/hearing080509_ma sters.pdf).

Peterson, H.H., and W.G. Tomek. "How Much of Commodity Price Behavior can a Rational Expectations Storage Model Explain?” Agricultural Economics 33 (2005):289-303.

Phillips, P.C.B., and J. Yu. "Dating the Timeline of Financial Bubbles during the Subprime Crisis.” Quantitative Economics 2 (2011):455-91.

Phillips, P.C.B., and J. Yu. "Limit Theory for Dating the Origination and Collapse of Mildly Explosive Periods in Time Series Data.” Working Paper, Sim Kee Boon Institute for Financial Economics, Singapore Management University, 2009.

Phillips, P.C., S.P. Shi, and J. Yu. “Testing for Multiple Bubbles.” Cowles Foundation Discussion Paper No.1843, 2012.

Phillips, P.C.B., and T. Magdalinos. "Limit Theory for Moderate Deviations from a Unit Root.” Journal of Econometrics 136 (2007a):115-30. 
Phillips, P.C.B., and T. Magdalinos. "Limit Theory for Moderate Deviations from a Unit Root under Weak Dependence.” in Refinement of Econometric Estimation and Test Procedures. G.D.A. Phillips, and E. Tzavalis, eds. pp. 123-162. Cambridge, UK: Cambridge University Press, 2007b.

Phillips, P.C.B., Y. Wu, and J. Yu. "Explosive Behavior in the 1990s NASDAQ: When did Exuberance Escalate Asset Values?” International Economic Review 52 (2011):201-26.

Piesse, J., and C. Thirtle "Three bubbles and a panic: An explanatory review of recent food commodity price events.” Food Policy 34 (2009):119-29.

Samuelson, P.A. "Proof That Properly Anticipated Prices Fluctuate Randomly.” Industrial Management Review 6 (1965)

Shiller, R.J. Irrational exuberance. Princeton, NJ: Princeton University Press, 2005.

Summers, L.H. “Does the Stock Market Rationally Reflect Fundamental Values?” The Journal of Finance 41 (1986):591-601.

Tomek, W.G., and H.H. Peterson. "Risk management in agricultural markets: A review.” Journal of Futures Markets 21 (2001):953-85.

Tomek, W.G., and H.H. Peterson. "Implications of Commodity Price Behavior for Marketing Strategies.” American Journal of Agricultural Economics 87 (2005):1258-64.

Wang, D., and W.G. Tomek. "Commodity Prices and Unit Root Tests.” American Journal of Agricultural Economics 89 (2007):873-89.

White, J.S. "The Limiting Distribution of the Serial Correlation Coefficient in the Explosive Case.” The Annals of Mathematical Statistics 29 (1958): 1188-97.

Williams, J.C. and B.D. Wright. Storage and commodity markets. Cambridge, UK: Cambridge University Press, 1991. 


\section{Endnotes}

${ }^{1}$ The SADF statistic here is based on a backward-expanding window, different from the SADF statistic in PWY (2011) and PY(2011) where a forward-expanding window is used.

${ }^{2}$ Specifically, the asymptotic distribution of $S A D F_{r_{2}}$ (based on a backward-expanding window) follows

$$
F_{r_{2}}^{r_{0}}=\operatorname{Sup}_{r_{1} \in\left[0, r_{2}-r_{0}\right]}\left\{\frac{\frac{1}{2} r_{w}\left[W\left(r_{2}\right)^{2}-W\left(r_{1}\right)^{2}-r_{w}\right]-\int_{r_{1}}^{r_{2}} W(r) d r\left[W\left(r_{2}\right)-W\left(r_{1}\right)\right]}{r_{w}^{1 / 2}\left\{r_{w} \int_{r_{1}}^{r_{2}} W(r)^{2} d r-\left[\int_{r_{1}}^{r_{2}} W(r) d r\right]^{2}\right\}^{1 / 2}}\right\} \text {, where } r_{w}=r_{2}-r_{1} \text {. }
$$

${ }^{3}$ In the case when risk premiums exist, the futures prices need to be adjusted by a constant or time-varying term.

${ }^{4}$ In addition, we do not include prices from the last trading month, which tend to present large price variabilities.

${ }^{5}$ The minimum window size is chosen so that the chance of finding explosive periods is maximized and there are a sufficient number of observations to estimate equation (2).

${ }^{6}$ To see this, note that the bubble testing procedure is based on log prices. So a unit drift term essentially implies that $\log \left(F_{t}^{T}\right)=1+\log \left(F_{t-1}^{T}\right)+\varepsilon_{t}$.

${ }^{7}$ Coefficient estimates in first-order autoregressions obtained from OLS are well known to be downward biased. In PWY (2011), the OLS estimates are adjusted for a small-sample bias correction, which are computed from simulation. The new estimate is referred to as the indirect estimate. Here we do not take into account this modification. 


\section{Tables and Figures}

Table 1. GSADF Testing Results for Individual Agricultural Futures Contract Prices, 1970-2011

\begin{tabular}{|c|c|c|c|c|c|c|c|c|c|c|c|c|}
\hline Year & Corn & Soy & SOil & Wheat & KWheat & Cocoa & Cotton & Coffee & Sugar & FCatt & LCatt & LHog \\
\hline 1970 & $* * *$ & $* * *$ & & & & & & & & & $* *$ & $* * *$ \\
\hline 1971 & & & & & & & $*$ & & & & $*$ & \\
\hline 1972 & $*$ & & & & & & $* *$ & & $* * *$ & & $* *$ & \\
\hline 1973 & $* *$ & $* * *$ & & $* *$ & $* * *$ & $* * *$ & $* * *$ & & & $* * *$ & $* * *$ & $*$ \\
\hline 1974 & $* * *$ & $* * *$ & $* *$ & & & & & $* *$ & $* * *$ & $* *$ & $* *$ & \\
\hline 1975 & & * & & & & & & $* * *$ & $* *$ & & & \\
\hline 1976 & & $* * *$ & & & & $* * *$ & $* * *$ & $* * *$ & & $* *$ & & \\
\hline 1977 & & & & & & & $* *$ & $* * *$ & & & $*$ & \\
\hline 1978 & $* * *$ & & & $* * *$ & $* *$ & & & $* * *$ & $* * *$ & $*$ & & \\
\hline 1979 & $* * *$ & $* * *$ & & $* * *$ & $* * *$ & & & $* * *$ & & & & \\
\hline 1980 & $*$ & $* *$ & $*$ & & & & & $* *$ & $* *$ & $* * *$ & $*$ & \\
\hline 1981 & & & & $* *$ & $* *$ & $* * *$ & * & $* * *$ & $*$ & & & \\
\hline 1982 & $* *$ & & & $* *$ & $* *$ & & & & $* * *$ & & & \\
\hline 1983 & $*$ & $* * *$ & $* * *$ & & & & & $* *$ & $* * *$ & & & \\
\hline 1984 & & & & & & & & $* *$ & $* *$ & & & \\
\hline 1985 & & & & & & & $* * *$ & $* *$ & $* * *$ & $* * *$ & $* *$ & $* * *$ \\
\hline 1986 & & $* * *$ & $* *$ & $* * *$ & $* * *$ & & & $* * *$ & & & & $* * *$ \\
\hline 1987 & & $* * *$ & & & $* * *$ & & & & & & $* *$ & \\
\hline 1988 & $* * *$ & $* * *$ & $* *$ & & $* *$ & & & $* * *$ & & & & \\
\hline 1989 & & & & & & & & $* * *$ & & & & \\
\hline 1990 & & & & & & & & $* *$ & & & & \\
\hline 1991 & & & & & & & & & & $* *$ & $* * *$ & $* * *$ \\
\hline 1992 & & & & $* *$ & $* * *$ & & & & & $*$ & & \\
\hline 1993 & $* *$ & $* * *$ & & & $* *$ & & & & $* * *$ & & & $* * *$ \\
\hline 1994 & & & * & $* *$ & & & & $* * *$ & & $* * *$ & $* *$ & $* * *$ \\
\hline 1995 & & & & $*$ & $* * *$ & & $* *$ & $* *$ & $*$ & & $* *$ & $* * *$ \\
\hline 1996 & $* *$ & & & $* * *$ & $* * *$ & & & & & $* * *$ & & $* *$ \\
\hline 1997 & & $* *$ & & & $* *$ & & & & & $*$ & & $* *$ \\
\hline 1998 & & & & & & & & & $* *$ & & $* *$ & $* * *$ \\
\hline 1999 & $*$ & $*$ & $* * *$ & & & & $*$ & $* * *$ & $* *$ & & & $* * *$ \\
\hline \multicolumn{13}{|l|}{2000} \\
\hline 2001 & $* * *$ & & $* *$ & & & $* * *$ & $* * *$ & & & & $* * *$ & \\
\hline 2002 & & & & & & & & & & $* * *$ & & $* * *$ \\
\hline 2003 & & $* *$ & & & & $* *$ & & & $* *$ & $* * *$ & $* *$ & \\
\hline 2004 & & & & & & $* * *$ & & & $* * *$ & & & \\
\hline 2005 & & $*$ & & & & & & & & & & \\
\hline 2006 & & & & & & $* * *$ & & & $*$ & & * & \\
\hline 2007 & & & & & $*$ & & & & & & & \\
\hline 2008 & $* *$ & $* *$ & $* *$ & & & $*$ & $* *$ & & $* * *$ & & & \\
\hline 2009 & & & & & & & & & $* * *$ & & & $* *$ \\
\hline 2010 & & & & & & & $* * *$ & $* * *$ & & $* * *$ & & \\
\hline \multicolumn{13}{|l|}{2011} \\
\hline Count & & & $*$ & $* *$ & $* * *$ & & & & $*$ & $* *$ & $* * *$ & \\
\hline & $1970-1990$ & & 13 & 31 & 50 & & 1991-2011 & & 13 & 27 & 33 & \\
\hline
\end{tabular}

Notes: The asterisks *,**,**** indicate that the GSADF statistic exceeds the $90 \%, 95 \%$, and $99 \%$ critical value for individual contract prices, respectively. Critical values are obtained from Monte Carlo simulations with 10,000 replications. 
Table 2. Number of Days with Bubbles based on SADF Test for Individual Agricultural Futures Contracts, 1970-2011 ( $h=5$ days)

\begin{tabular}{|c|c|c|c|c|c|c|c|c|c|c|c|c|c|}
\hline Year & Corn & Soy & SOil & Wheat & KWheat & Cocoa & Cotton & Coffee & Sugar & FCatt & LCatt & LHog & Sum \\
\hline \multicolumn{14}{|c|}{$1970-1990$} \\
\hline 1970 & 35 & 32 & 14 & & & 12 & & & & & 5 & 23 & 121 \\
\hline 1971 & 11 & 35 & 23 & & 5 & & 11 & & 15 & & 13 & 12 & 125 \\
\hline 1972 & & & & 11 & 12 & & 36 & & 5 & & 21 & 6 & 91 \\
\hline 1973 & 39 & 29 & 15 & 7 & 8 & 69 & 97 & & & 39 & 53 & 33 & 389 \\
\hline 1974 & 16 & 26 & 26 & & & 14 & & 35 & 48 & 12 & 31 & 28 & 236 \\
\hline 1975 & & & & & & 8 & & 37 & 12 & 5 & & 20 & 82 \\
\hline 1976 & & 44 & & & & 34 & 35 & 49 & & 24 & & & 186 \\
\hline 1977 & 38 & & & & 49 & 12 & & 72 & 6 & & & & 177 \\
\hline 1978 & 17 & & & & & 12 & & 20 & 31 & 46 & 7 & 14 & 147 \\
\hline 1979 & 20 & 10 & & 30 & 36 & & & 39 & & & & 7 & 142 \\
\hline 1980 & 6 & 20 & 23 & & 5 & 12 & & 21 & 42 & 14 & 5 & & 148 \\
\hline 1981 & 21 & 7 & & 14 & 6 & 17 & 65 & 30 & 50 & & 9 & 6 & 225 \\
\hline 1982 & 52 & & & & 5 & 36 & & & 66 & & & & 159 \\
\hline 1983 & 18 & 35 & 53 & & 5 & & 6 & 28 & 15 & & & 10 & 170 \\
\hline 1984 & & & 7 & & 7 & & & 11 & 17 & & & 19 & 61 \\
\hline 1985 & 41 & 5 & 5 & 21 & 20 & & 10 & 31 & 9 & & 5 & 21 & 168 \\
\hline 1986 & 5 & & 18 & & 15 & & 48 & 35 & 6 & 6 & & 25 & 158 \\
\hline 1987 & & 27 & 6 & 6 & 11 & & 29 & & 6 & 12 & & & 97 \\
\hline 1988 & 30 & 32 & 15 & & & 20 & & 14 & 16 & & & 5 & 132 \\
\hline 1989 & & 6 & 5 & & 9 & & 8 & 42 & & 5 & & 6 & 81 \\
\hline 1990 & & & & 18 & & 19 & 20 & 6 & & & & 15 & 78 \\
\hline \multirow[t]{2}{*}{ Sum } & 349 & 308 & 210 & 107 & 193 & 265 & 365 & 470 & 344 & 163 & 149 & 250 & 3173 \\
\hline & $(6.6)$ & $(5.8)$ & $(4.0)$ & $(2.0)$ & (3.6) & (5.1) & $(6.9)$ & $(10.4)$ & $(6.6)$ & (3.4) & $(2.8)$ & (4.7) & $(5.1)$ \\
\hline \multicolumn{14}{|c|}{ 1991-2011 } \\
\hline 1991 & & 5 & & & & & & & & & 11 & 10 & 26 \\
\hline 1992 & & & & 28 & 29 & 5 & 5 & & & 31 & 6 & & 104 \\
\hline 1993 & & 18 & & 9 & 9 & & & & 29 & 5 & 6 & & 76 \\
\hline 1994 & & & 6 & 8 & 11 & & 8 & 97 & & 13 & 6 & 70 & 219 \\
\hline 1995 & 7 & & & 7 & 8 & & & 5 & & & 7 & & 34 \\
\hline 1996 & 11 & 7 & & 20 & 31 & & & & & 7 & 13 & 12 & 101 \\
\hline 1997 & & 6 & & 5 & 9 & & & 15 & & 18 & 7 & & 60 \\
\hline 1998 & 6 & & 5 & 15 & 7 & & 5 & & 55 & & 16 & 65 & 174 \\
\hline 1999 & 7 & 34 & 42 & & 6 & 20 & 8 & & 45 & & & 30 & 192 \\
\hline 2000 & 40 & 6 & & & & & 6 & & 59 & & & & 111 \\
\hline 2001 & & 12 & 5 & & 5 & 21 & 97 & & & 7 & 19 & & 166 \\
\hline 2002 & & & & 5 & 5 & 12 & & & 8 & 14 & 12 & 54 & 110 \\
\hline 2003 & & 30 & 28 & & & 6 & 12 & & 16 & 25 & 53 & 5 & 175 \\
\hline 2004 & 21 & 12 & & & & & 33 & & 16 & 28 & 8 & & 118 \\
\hline 2005 & & 13 & & & & & & & 21 & & & 9 & 43 \\
\hline 2006 & 11 & & & 5 & 7 & 9 & & 10 & 43 & 11 & 9 & & 105 \\
\hline 2007 & 4 & & & 5 & 18 & 5 & 12 & & 9 & & & 8 & 61 \\
\hline 2008 & 37 & 28 & 62 & 17 & 40 & 34 & 36 & 5 & 34 & 16 & 22 & 25 & 356 \\
\hline 2009 & 9 & & & & & & 8 & & 21 & & & 15 & 53 \\
\hline 2010 & 5 & 8 & 11 & 12 & 12 & & 57 & 8 & 10 & 84 & 13 & & 220 \\
\hline 2011 & & 12 & 8 & & & & & 6 & & 16 & & 7 & 49 \\
\hline \multirow[t]{2}{*}{ Sum } & 158 & 191 & 167 & 136 & 197 & 112 & 287 & 146 & 366 & 275 & 208 & 310 & 2553 \\
\hline & (3.0) & (3.6) & $(3.2)$ & $(2.6)$ & (3.7) & $(2.1)$ & (5.5) & $(2.8)$ & $(7.0)$ & $(5.2)$ & (3.9) & (5.9) & $(4.0)$ \\
\hline \multirow[t]{2}{*}{ Total } & 507 & 499 & 377 & 243 & 390 & 377 & 652 & 616 & 710 & 438 & 357 & 560 & 5726 \\
\hline & $(4.8)$ & (4.7) & $(3.6)$ & (2.3) & (3.7) & (3.6) & (6.2) & (6.3) & $(6.8)$ & (4.3) & (3.4) & (5.3) & (4.6) \\
\hline
\end{tabular}

Notes: Each explosive episode needs to last at least 5 days to be considered a bubble. Each cell represents the total number of days with bubbles for a given commodity during a given year. Numbers in parentheses are the percentages of days with bubbles during each sample period. Days less than 5 occur due to bubbles originated at the end of the first year and contiunes into the following year. 
Table 3. Number of Days with Bubbles based on SADF Test for Individual Agricultural Futures Contracts, 1970-2011 ( $h=10$ days)

\begin{tabular}{|c|c|c|c|c|c|c|c|c|c|c|c|c|c|}
\hline Year & Corn & Soy & SOil & Wheat & KWheat & Cocoa & Cotton & Coffee & Sugar & FCatt & LCatt & LHog & Sum \\
\hline \multicolumn{14}{|c|}{$1970-1990$} \\
\hline 1970 & 24 & 27 & & & & & & & & & & 23 & 74 \\
\hline 1971 & & 28 & & & & & 11 & & 15 & & 13 & & 67 \\
\hline 1972 & & & & 11 & 12 & & 25 & & 5 & & 21 & & 74 \\
\hline 1973 & 39 & 15 & 15 & & & 69 & 91 & & & 33 & 44 & 33 & 339 \\
\hline 1974 & 11 & 19 & 17 & & & & & 28 & 48 & & 17 & 22 & 162 \\
\hline 1975 & & & & & & & & 31 & 12 & & & 20 & 63 \\
\hline 1976 & & 44 & & & & 34 & 35 & 32 & & & & & 145 \\
\hline 1977 & 38 & & & & 35 & & & 57 & & & & & 130 \\
\hline 1978 & 17 & & & & & & & 15 & 31 & 30 & & 14 & 107 \\
\hline 1979 & 20 & 10 & & 18 & 36 & & & 34 & & & & & 118 \\
\hline 1980 & & & 15 & & & 12 & & & 16 & 14 & & & 57 \\
\hline 1981 & 10 & & & 14 & & 17 & 60 & 12 & 45 & & & & 158 \\
\hline 1982 & 36 & & & & & 31 & & & 59 & & & & 126 \\
\hline 1983 & 13 & 30 & 53 & & & & & 12 & 15 & & & & 123 \\
\hline 1984 & & & & & & & & 11 & 10 & & & & 21 \\
\hline 1985 & 41 & & & 21 & 20 & & 15 & 21 & & & & & 118 \\
\hline 1986 & & & & & 15 & & 28 & 45 & & & & 25 & 113 \\
\hline 1987 & & 22 & & & 11 & & 22 & & & 12 & & & 67 \\
\hline 1988 & 25 & 27 & 15 & & & & & & 14 & & & & 81 \\
\hline 1989 & & & & & & & & 33 & & & & & 33 \\
\hline 1990 & & & & 18 & & 10 & 20 & & & & & & 48 \\
\hline Sum & $\begin{array}{r}274 \\
(5.2) \\
\end{array}$ & $\begin{array}{r}222 \\
(4.2)\end{array}$ & $\begin{array}{r}115 \\
(2.2) \\
\end{array}$ & $\begin{array}{r}82 \\
(1.5)\end{array}$ & $\begin{array}{r}129 \\
(2.4)\end{array}$ & $\begin{array}{r}173 \\
(3.3) \\
\end{array}$ & $\begin{array}{r}307 \\
(5.8)\end{array}$ & $\begin{array}{r}331 \\
(7.3)\end{array}$ & $\begin{array}{r}270 \\
(5.2)\end{array}$ & $\begin{array}{r}89 \\
(1.9)\end{array}$ & $\begin{array}{r}95 \\
(1.8) \\
\end{array}$ & $\begin{array}{r}137 \\
(2.6)\end{array}$ & $\begin{array}{l}2224 \\
(3.6) \\
\end{array}$ \\
\hline \multicolumn{14}{|c|}{$1991-2011$} \\
\hline 1991 & & & & & & & & & & & 11 & 10 & 21 \\
\hline 1992 & & & & 22 & 21 & & & & & 23 & & & 66 \\
\hline 1993 & & 18 & & 9 & 9 & & & & 17 & & & & 53 \\
\hline 1994 & & & & 1 & 11 & & & 97 & & & & 45 & 154 \\
\hline 1995 & & & & & & & & & & & & & 0 \\
\hline 1996 & & & & 15 & 31 & & & & & & 13 & 12 & 71 \\
\hline 1997 & & & & & & & & 10 & & 18 & & & 28 \\
\hline 1998 & & & & 15 & & & & & 15 & & & 56 & 86 \\
\hline 1999 & & 20 & 35 & & & 12 & & & 45 & & & 24 & 136 \\
\hline 2000 & 31 & & & & & & & & 54 & & & & 85 \\
\hline 2001 & & & & & & 16 & 80 & & & & 11 & & 107 \\
\hline 2002 & & & & & & 12 & & & & & & 48 & 60 \\
\hline 2003 & & 30 & 28 & & & & 12 & & 10 & 16 & 53 & & 149 \\
\hline 2004 & 10 & & & & & & 33 & & 10 & & & & 53 \\
\hline 2005 & & & & & & & & & 21 & & & & 21 \\
\hline 2006 & & & & & & & & 10 & 38 & 11 & & & 59 \\
\hline 2007 & 4 & & & & 12 & & & & 9 & & & & 25 \\
\hline 2008 & 13 & 23 & 46 & & 34 & 17 & 22 & & 28 & 11 & 11 & 10 & 215 \\
\hline 2009 & & & & & & & & & 21 & & & 15 & 36 \\
\hline 2010 & & & 11 & & & & 57 & & & 70 & & & 138 \\
\hline 2011 & & 12 & & & & & & & & & & & 12 \\
\hline Sum & $\begin{array}{r}58 \\
(1.1)\end{array}$ & $\begin{array}{r}103 \\
(1.9)\end{array}$ & $\begin{array}{r}120 \\
(2.3)\end{array}$ & $\begin{array}{r}62 \\
(1.2)\end{array}$ & $\begin{array}{r}118 \\
(2.2)\end{array}$ & $\begin{array}{r}57 \\
(1.1)\end{array}$ & $\begin{array}{r}204 \\
(3.9)\end{array}$ & $\begin{array}{r}117 \\
(2.2)\end{array}$ & $\begin{array}{r}268 \\
(5.1)\end{array}$ & $\begin{array}{r}149 \\
(2.8)\end{array}$ & $\begin{array}{r}99 \\
(1.9)\end{array}$ & $\begin{array}{r}220 \\
(4.2)\end{array}$ & $\begin{array}{l}1575 \\
(2.5)\end{array}$ \\
\hline Total & $\begin{array}{r}332 \\
(3.1) \\
\end{array}$ & $\begin{array}{r}325 \\
(3.1) \\
\end{array}$ & $\begin{array}{r}235 \\
(2.2) \\
\end{array}$ & $\begin{array}{r}144 \\
(1.4) \\
\end{array}$ & $\begin{array}{r}247 \\
(2.3) \\
\end{array}$ & $\begin{array}{r}230 \\
(2.2) \\
\end{array}$ & $\begin{array}{r}511 \\
(4.9) \\
\end{array}$ & $\begin{array}{r}448 \\
(4.6) \\
\end{array}$ & $\begin{array}{r}538 \\
(5.1) \\
\end{array}$ & $\begin{array}{r}238 \\
(2.4) \\
\end{array}$ & $\begin{array}{r}194 \\
(1.8) \\
\end{array}$ & $\begin{array}{r}357 \\
(3.4) \\
\end{array}$ & $\begin{array}{r}3799 \\
(3.0) \\
\end{array}$ \\
\hline
\end{tabular}

Notes: Each explosive episode needs to last at least 10 days to be considered a bubble. Each cell represents the total number of days with bubbles for a given commodity during a given year. Numbers in parentheses are the percentages of days with bubbles during each sample period. Days less than 5 occur due to bubbles originated at the end of the first year and contiunes into the following year. 
Table 4. Length of Bubbles for Individual Agricultural Futures Contracts, 1970-2011

\begin{tabular}{|c|c|c|c|c|c|c|c|c|c|c|c|c|}
\hline \multirow[b]{2}{*}{ Commodity } & \multicolumn{6}{|c|}{$h=5$ days } & \multicolumn{6}{|c|}{$h=10$ days } \\
\hline & $\mathbf{N}$ & Mean & Std. Dev. & Min & Max & Skewness & $\mathbf{N}$ & Mean & Std. Dev. & Min & Max & Skewness \\
\hline & \multicolumn{12}{|c|}{$1970-1990$} \\
\hline Corn & 25 & 14 & 11 & 5 & 41 & 1.18 & 12 & 23 & 11 & 10 & 41 & 0.50 \\
\hline Soy & 24 & 13 & 11 & 5 & 44 & 1.48 & 10 & 22 & 11 & 10 & 44 & 0.55 \\
\hline SOil & 19 & 11 & 11 & 5 & 53 & 3.22 & 5 & 23 & 17 & 15 & 53 & 1.49 \\
\hline Wheat & 9 & 12 & 6 & 5 & 21 & 0.27 & 5 & 16 & 4 & 11 & 21 & -0.31 \\
\hline KWheat & 18 & 11 & 6 & 5 & 20 & 0.58 & 8 & 16 & 4 & 11 & 20 & -0.11 \\
\hline Cocoa & 24 & 11 & 9 & 5 & 45 & 2.81 & 10 & 17 & 11 & 10 & 45 & 2.01 \\
\hline Cotton & 23 & 16 & 13 & 5 & 45 & 1.12 & 13 & 24 & 12 & 10 & 45 & 0.73 \\
\hline Coffee & 36 & 13 & 10 & 5 & 35 & 1.40 & 16 & 21 & 10 & 10 & 35 & 0.40 \\
\hline Sugar & 25 & 14 & 11 & 5 & 59 & 2.81 & 14 & 19 & 13 & 10 & 59 & 2.48 \\
\hline FCatt & 18 & 9 & 5 & 5 & 23 & 1.52 & 6 & 15 & 5 & 10 & 23 & 0.81 \\
\hline LCatt & 14 & 11 & 6 & 5 & 24 & 1.06 & 6 & 16 & 5 & 10 & 24 & 0.38 \\
\hline LHog & 27 & 9 & 7 & 5 & 33 & 2.21 & 8 & 17 & 8 & 10 & 33 & 1.21 \\
\hline All & 262 & 12 & 9 & 5 & 59 & 2.11 & 113 & 20 & 10 & 10 & 59 & 1.56 \\
\hline \multirow[t]{2}{*}{ Jarque-Bera p } & \multicolumn{6}{|c|}{0.000} & \multicolumn{6}{|c|}{0.000} \\
\hline & \multicolumn{12}{|c|}{ 1991-2011 } \\
\hline Corn & 20 & 8 & 4 & 5 & 17 & 1.54 & 4 & 15 & 3 & 10 & 17 & -0.63 \\
\hline Soy & 20 & 10 & 6 & 5 & 30 & 1.99 & 6 & 17 & 7 & 10 & 30 & 0.87 \\
\hline SOil & 13 & 13 & 9 & 5 & 35 & 1.35 & 6 & 20 & 10 & 11 & 35 & 0.53 \\
\hline Wheat & 17 & 8 & 5 & 5 & 22 & 1.80 & 4 & 16 & 5 & 10 & 22 & 0.35 \\
\hline KWheat & 18 & 11 & 7 & 5 & 31 & 1.42 & 6 & 20 & 7 & 12 & 31 & 0.48 \\
\hline Cocoa & 13 & 9 & 4 & 5 & 17 & 0.88 & 4 & 14 & 3 & 12 & 17 & 0.07 \\
\hline Cotton & 21 & 14 & 14 & 5 & 57 & 1.97 & 8 & 26 & 16 & 10 & 57 & 0.82 \\
\hline Coffee & 10 & 15 & 14 & 5 & 50 & 1.67 & 5 & 23 & 16 & 10 & 50 & 0.88 \\
\hline Sugar & 31 & 12 & 8 & 5 & 39 & 1.54 & 15 & 18 & 7 & 10 & 39 & 1.74 \\
\hline FCatt & 27 & 10 & 8 & 5 & 42 & 2.81 & 8 & 19 & 10 & 11 & 42 & 1.64 \\
\hline LCatt & 23 & 9 & 5 & 5 & 25 & 2.17 & 7 & 14 & 5 & 11 & 25 & 1.45 \\
\hline LHog & 25 & 12 & 9 & 5 & 45 & 2.26 & 12 & 18 & 9 & 10 & 45 & 1.97 \\
\hline All & 238 & 11 & 8 & 5 & 57 & 2.59 & 85 & 19 & 9 & 10 & 57 & 1.90 \\
\hline Jarque-Bera p & \multicolumn{6}{|c|}{0.000} & \multicolumn{6}{|c|}{0.000} \\
\hline
\end{tabular}

Notes: Each explosive episode needs to last at least 10 or 5 days to be considered a bubble. Descriptive statistics are based on the length of bubbles. The Jarque-Bera test is performed to check whether the length of bubbles during each sub-period is normally distributed when pooled across all markets. The total number of days with bubbles implied from this table may not equal the numbers shown in tables 2 and 3 due to rounding. 
Table 5. Cumulative Daily Returns for Individual Agricultural Futures Contracts during Bubble Periods ( $h=5$ days), 1970-1990 versus 1991-2011

\begin{tabular}{|c|c|c|c|c|c|c|c|c|}
\hline \multirow[b]{2}{*}{ Commodity } & \multicolumn{4}{|c|}{ Positive Bubble } & \multicolumn{4}{|c|}{ Negative Bubble } \\
\hline & $\mathbf{N}$ & Length & $\begin{array}{c}\text { \% Return } \\
\text { Start to Peak }\end{array}$ & $\begin{array}{c}\text { \% Return } \\
\text { Peak to End }\end{array}$ & $\mathbf{N}$ & Length & $\begin{array}{c}\text { \% Return } \\
\text { Start to } \\
\text { Trough }\end{array}$ & $\begin{array}{c}\text { \% Return } \\
\text { Trough to } \\
\text { End }\end{array}$ \\
\hline & \multicolumn{8}{|c|}{$1970-1990$} \\
\hline Corn & 15 & 12 & 11.9 & -3.3 & 10 & 16 & -5.6 & 1.2 \\
\hline Soy & 21 & 14 & 11.0 & -2.4 & 3 & 6 & -2.4 & 0.3 \\
\hline SOil & 11 & 15 & 14.1 & -4.4 & 8 & 6 & -3.3 & 1.3 \\
\hline Wheat & 6 & 9 & 10.0 & -3.5 & 3 & 18 & -8.5 & 0.6 \\
\hline KWheat & 9 & 11 & 9.6 & -3.0 & 9 & 10 & -3.6 & 0.7 \\
\hline Сосоа & 14 & 12 & 11.2 & -3.1 & 10 & 10 & -6.1 & 1.1 \\
\hline Cotton & 16 & 15 & 10.1 & -2.5 & 7 & 18 & -5.7 & 1.3 \\
\hline Coffee & 20 & 14 & 12.4 & -1.9 & 16 & 12 & -12.1 & 4.0 \\
\hline Sugar & 12 & 13 & 22.6 & -5.4 & 13 & 15 & -14.6 & 3.2 \\
\hline FCatt & 8 & 12 & 7.0 & -1.4 & 10 & 7 & -6.9 & 1.5 \\
\hline LCatt & 6 & 12 & 7.0 & -2.0 & 8 & 9 & -9.3 & 2.5 \\
\hline LHog & 12 & 11 & 6.7 & -1.2 & 15 & 8 & -5.5 & 1.7 \\
\hline \multirow[t]{3}{*}{ All } & 150 & 13 & 11.5 & -2.8 & 112 & 11 & -7.7 & 2.0 \\
\hline & & & $(0.00)$ & $(0.00)$ & & & $(0.00)$ & $(0.00)$ \\
\hline & \multicolumn{8}{|c|}{ 1991-2011 } \\
\hline Corn & 10 & 8 & 4.8 & -0.9 & 10 & 8 & -5.7 & 1.2 \\
\hline Soy & 10 & 11 & 6.8 & -1.0 & 10 & 8 & -5.0 & 0.9 \\
\hline SOil & 6 & 13 & 10.5 & -1.8 & 7 & 13 & -10.8 & 2.2 \\
\hline Wheat & 14 & 8 & 8.7 & -2.3 & 3 & 9 & -3.1 & 0.3 \\
\hline KWheat & 14 & 12 & 11.1 & -2.5 & 4 & 7 & -3.3 & 0.4 \\
\hline Сосоа & 9 & 9 & 7.8 & -1.0 & 4 & 8 & -4.6 & 1.0 \\
\hline Cotton & 7 & 15 & 12.4 & -4.6 & 14 & 13 & -8.4 & 2.1 \\
\hline Coffee & 9 & 16 & 19.0 & -4.9 & 1 & 5 & -13.0 & 7.0 \\
\hline Sugar & 16 & 14 & 11.2 & -2.0 & 15 & 10 & -7.1 & 2.5 \\
\hline FCatt & 18 & 12 & 3.3 & -0.7 & 9 & 7 & -3.5 & 1.1 \\
\hline LCatt & 12 & 10 & 3.0 & -0.9 & 11 & 8 & -3.6 & 1.3 \\
\hline LHog & 6 & 7 & 3.3 & -0.4 & 19 & 14 & -9.3 & 2.4 \\
\hline \multirow[t]{2}{*}{ All } & 131 & 11 & 8.2 & -1.8 & 107 & 10 & -6.6 & 1.7 \\
\hline & & & $(0.00)$ & $(0.00)$ & & & $(0.00)$ & $(0.00)$ \\
\hline \multicolumn{9}{|c|}{ Differences between 1970-1990 and 1991-2011 } \\
\hline & -19 & $\begin{array}{c}-2 \\
(0.14)\end{array}$ & $\begin{array}{c}-3.3 \\
(0.01)\end{array}$ & $\begin{array}{c}1.0 \\
(0.02)\end{array}$ & -5 & $\begin{array}{c}-1 \\
(0.36)\end{array}$ & $\begin{array}{c}1.1 \\
(0.22)\end{array}$ & $\begin{array}{c}-0.2 \\
(0.42)\end{array}$ \\
\hline
\end{tabular}

Notes: Each explosive episode needs to last at least 5 days to be considered as a bubble. Bubbles are positive when the average price during explosive periods is higher than the price at bubble origination dates, and negative when the opposite is true. Average lengths and percentage price changes are presetned in the table. $\mathrm{N}$ refers to the number of bubble periods. Numbers in parentheses are p-values for the test that the mean or difference equals zero. Differences may not match due to rounding. 
Table 6. Cumulative Daily Returns for Individual Agricultural Futures Contracts during Bubble Periods ( $h=5$ days), 1971-1976 versus 2006-2011

\begin{tabular}{|c|c|c|c|c|c|c|c|c|}
\hline \multirow[b]{2}{*}{ Commodity } & \multicolumn{4}{|c|}{ Positive } & \multicolumn{4}{|c|}{ Negative } \\
\hline & $\mathbf{N}$ & Length & $\begin{array}{c}\text { \% Return } \\
\text { Start to Peak }\end{array}$ & $\begin{array}{c}\text { \% Return } \\
\text { Peak to End }\end{array}$ & $\mathbf{N}$ & Length & $\begin{array}{l}\text { \% Return } \\
\text { Start to } \\
\text { Trough } \\
\end{array}$ & $\begin{array}{c}\text { \% Return } \\
\text { Trough to } \\
\text { End } \\
\end{array}$ \\
\hline & \multicolumn{8}{|c|}{$1971-1976$} \\
\hline Corn & 5 & 12 & 15.7 & -4.9 & 1 & 5 & -1.8 & 0.9 \\
\hline Soy & 8 & 17 & 16.3 & -4.2 & & & & \\
\hline SoyOil & 5 & 11 & 13.0 & -4.5 & 1 & 9 & -1.9 & 2.1 \\
\hline Wheat & 2 & 9 & 12.0 & -2.9 & & & & \\
\hline KWheat & 2 & 10 & 15.3 & -4.2 & 1 & 5 & -1.5 & 0.4 \\
\hline Сocoa & 7 & 17 & 16.1 & -5.1 & 1 & 8 & -6.9 & 0.5 \\
\hline Cotton & 8 & 20 & 15.1 & -3.5 & 2 & 11 & -2.1 & 0.9 \\
\hline Coffee & 6 & 14 & 11.2 & -1.6 & 3 & 12 & -12.4 & 3.7 \\
\hline Sugar & 3 & 23 & 48.7 & -9.6 & 1 & 12 & -14.0 & 0.9 \\
\hline FCatt & 3 & 12 & 9.0 & -2.5 & 7 & 6 & -7.3 & 1.3 \\
\hline LCatt & 5 & 13 & 7.5 & -2.3 & 4 & 13 & -13.9 & 3.9 \\
\hline LHog & 4 & 16 & 10.8 & -2.0 & 3 & 12 & -12.7 & 4.0 \\
\hline \multirow[t]{3}{*}{ All } & 58 & 15 & 15.2 & -3.9 & 24 & 10 & -8.9 & 2.3 \\
\hline & & & $(0.00)$ & $(0.00)$ & & & $(0.00)$ & $(0.00)$ \\
\hline & \multicolumn{8}{|c|}{ 2006-2011 } \\
\hline Corn & 5 & 8 & 6.5 & -1.6 & 4 & 7 & -7.2 & 0.6 \\
\hline Soy & 3 & 10 & 6.2 & -0.8 & 2 & 9 & -8.7 & 0.7 \\
\hline SoyOil & 3 & 12 & 10.5 & -3.4 & 4 & 11 & -11.9 & 2.7 \\
\hline Wheat & 7 & 6 & 8.9 & -2.6 & & & & \\
\hline KWheat & 8 & 10 & 10.5 & -2.9 & & & & \\
\hline Сocoa & 5 & 9 & 6.4 & -0.7 & 1 & 5 & -4.1 & 0.0 \\
\hline Cotton & 4 & 19 & 17.9 & -7.0 & 3 & 12 & -12.9 & 3.2 \\
\hline Coffee & 4 & 7 & 6.9 & -0.6 & & & & \\
\hline Sugar & 6 & 15 & 13.2 & -2.9 & 3 & 10 & -8.4 & 3.9 \\
\hline FCatt & 7 & 14 & 2.9 & -0.3 & 4 & 8 & -3.5 & 0.7 \\
\hline LCatt & 3 & 6 & 1.5 & -0.5 & 3 & 8 & -4.5 & 1.4 \\
\hline LHog & 2 & 8 & 3.5 & -0.6 & 4 & 10 & -6.0 & 2.8 \\
\hline \multirow[t]{5}{*}{ All } & 57 & 10 & 8.3 & -2.1 & 28 & 9 & -7.6 & 1.9 \\
\hline & & & $(0.00)$ & $(0.00)$ & & & $(0.00)$ & $(0.00)$ \\
\hline & \multicolumn{8}{|c|}{ Differences between 1971-1976 and 2006-2011 } \\
\hline & -1 & -5 & -7.0 & 1.8 & 4 & -0 & 1.2 & -0.4 \\
\hline & & $(0.01)$ & $(0.00)$ & $(0.01)$ & & $(0.78)$ & $(0.46)$ & $(0.61)$ \\
\hline
\end{tabular}

Notes: Each explosive episode needs to last at least 5 days to be considered as a bubble. Bubbles are positive when the average price during explosive periods is higher than the price at bubble origination dates, and negative when the opposite is true. Average lengths and percentage price changes are presetned in the table. $\mathrm{N}$ refers to the number of bubble periods. Numbers in parentheses are p-values for the test that the mean or difference equals zero. Differences may not match due to rounding. 
Table 7. Cumulative Daily Returns for Individual Agricultural Futures Contracts during Bubble Periods $(h=10$ days $), 1970-1990$ versus 1991-2011

\begin{tabular}{|c|c|c|c|c|c|c|c|c|}
\hline \multirow[b]{2}{*}{ Commodity } & \multicolumn{4}{|c|}{ Positive Bubble } & \multicolumn{4}{|c|}{ Negative Bubble } \\
\hline & $\mathbf{N}$ & Length & $\begin{array}{c}\text { \% Return } \\
\text { Start to Peak }\end{array}$ & $\begin{array}{c}\text { \% Return } \\
\text { Peak to End }\end{array}$ & $\mathbf{N}$ & Length & $\begin{array}{c}\text { \% Return } \\
\text { Start to } \\
\text { Trough }\end{array}$ & $\begin{array}{c}\text { \% Return } \\
\text { Trough to } \\
\text { End }\end{array}$ \\
\hline & \multicolumn{8}{|c|}{$1970-1990$} \\
\hline Corn & 8 & 19 & 17.7 & -5.0 & 4 & 31 & -9.8 & 2.1 \\
\hline Soy & 10 & 22 & 17.2 & -3.5 & & & & \\
\hline SOil & 5 & 23 & 24.0 & -8.0 & & & & \\
\hline Wheat & 2 & 15 & 17.9 & -7.3 & 3 & 18 & -8.5 & 0.6 \\
\hline KWheat & 5 & 16 & 13.5 & -4.2 & 3 & 17 & -5.6 & 1.4 \\
\hline Сосоа & 6 & 19 & 17.2 & -4.9 & 4 & 15 & -9.3 & 1.4 \\
\hline Cotton & 8 & 24 & 17.1 & -4.0 & 5 & 24 & -6.8 & 1.6 \\
\hline Coffee & 9 & 22 & 21.4 & -3.2 & 7 & 19 & -16.7 & 5.2 \\
\hline Sugar & 6 & 19 & 37.4 & -9.1 & 8 & 20 & -19.1 & 4.4 \\
\hline FCatt & 4 & 16 & 9.9 & -2.7 & 2 & 12 & -11.3 & 3.6 \\
\hline LCatt & 4 & 15 & 7.2 & -2.9 & 2 & 19 & -18.6 & 4.8 \\
\hline LHog & 5 & 18 & 13.0 & -2.0 & 3 & 15 & -13.0 & 4.3 \\
\hline \multirow[t]{3}{*}{ All } & 72 & 20 & 18.4 & -4.6 & 41 & 20 & -12.7 & 3.2 \\
\hline & & & $(0.00)$ & $(0.00)$ & & & $(0.00)$ & $(0.00)$ \\
\hline & \multicolumn{8}{|c|}{ 1991-2011 } \\
\hline Corn & 2 & 14 & 8.4 & -2.1 & 2 & 16 & -6.4 & 1.9 \\
\hline Soy & 4 & 18 & 12.3 & -1.7 & 2 & 16 & -9.0 & 1.2 \\
\hline SOil & 4 & 16 & 12.0 & -2.7 & 2 & 28 & -23.1 & 6.8 \\
\hline Wheat & 3 & 16 & 13.9 & -3.6 & 1 & 15 & -4.6 & 0.9 \\
\hline KWheat & 6 & 20 & 15.3 & -3.4 & & & & \\
\hline Cocoa & 3 & 15 & 13.4 & -1.4 & 1 & 12 & -9.3 & 2.3 \\
\hline Cotton & 2 & 35 & 31.5 & -12.6 & 6 & 23 & -14.0 & 3.5 \\
\hline Coffee & 5 & 23 & 28.6 & -7.8 & & & & \\
\hline Sugar & 10 & 19 & 15.3 & -2.7 & 5 & 16 & -13.7 & 3.9 \\
\hline FCatt & 6 & 21 & 5.7 & -1.4 & 2 & 11 & -4.6 & 1.1 \\
\hline LCatt & 4 & 16 & 6.2 & -2.0 & 3 & 12 & -4.2 & 0.9 \\
\hline LHog & 1 & 12 & 4.5 & -0.3 & 11 & 19 & -13.2 & 3.2 \\
\hline \multirow[t]{4}{*}{ All } & 50 & 19 & 14.2 & -3.3 & 35 & 18 & -11.7 & 3.0 \\
\hline & & & $(0.00)$ & $(0.00)$ & & & $(0.00)$ & $(0.00)$ \\
\hline & \multicolumn{8}{|c|}{ Differences between 1970-1990 and 1991-2011 } \\
\hline & -22 & $\begin{array}{c}-1 \\
(0.67)\end{array}$ & $\begin{array}{c}-4.2 \\
(0.07)\end{array}$ & $\begin{array}{c}1.2 \\
(0.11)\end{array}$ & -6 & $\begin{array}{c}-2 \\
(0.47)\end{array}$ & $\begin{array}{c}1.0 \\
(0.58)\end{array}$ & $\begin{array}{c}-0.2 \\
(0.76)\end{array}$ \\
\hline
\end{tabular}

Notes: Each explosive episode needs to last at least 10 days to be considered as a bubble. Bubbles are positive when the average price during explosive periods is higher than the price at bubble origination dates, and negative when the opposite is true. Average lengths and percentage price changes are presetned in the table. $\mathrm{N}$ refers to the number of bubble periods. Numbers in parentheses are p-values for the test that the mean or difference equals zero. Differences may not match due to rounding. 
Table 8. Cumulative Daily Returns for Individual Agricultural Futures Contracts during Bubble Periods $(h=10$ days), 1971-1976 versus 2006-2011

\begin{tabular}{|c|c|c|c|c|c|c|c|c|}
\hline \multirow[b]{2}{*}{ Commodity } & \multicolumn{4}{|c|}{ Positive } & \multicolumn{4}{|c|}{ Negative } \\
\hline & $\mathbf{N}$ & Length & $\begin{array}{c}\text { \% Return } \\
\text { Start to Peak }\end{array}$ & $\begin{array}{c}\text { \% Return } \\
\text { Peak to End }\end{array}$ & $\mathbf{N}$ & Length & $\begin{array}{l}\text { \% Return } \\
\text { Start to } \\
\text { Trough }\end{array}$ & $\begin{array}{c}\text { \% Return } \\
\text { Trough to } \\
\text { End }\end{array}$ \\
\hline & \multicolumn{8}{|c|}{$1971-1976$} \\
\hline Corn & 3 & 17 & 21.6 & -8.1 & & & & \\
\hline Soy & 4 & 27 & 24.3 & -5.3 & & & & \\
\hline SoyOil & 2 & 16 & 22.6 & -8.4 & & & & \\
\hline Wheat & 1 & 11 & 13.1 & -2.4 & & & & \\
\hline KWheat & 1 & 12 & 15.5 & -4.8 & 2 & 19 & -18.6 & 4.8 \\
\hline Сосоа & 5 & 21 & 19.4 & -5.5 & & & & \\
\hline Cotton & 6 & 25 & 19.3 & -4.6 & 1 & 15 & -2.5 & 1.6 \\
\hline Coffee & 3 & 21 & 18.4 & -2.6 & 2 & 14 & -12.8 & 4.5 \\
\hline Sugar & 3 & 23 & 48.7 & -9.6 & 1 & 12 & -14.0 & 0.9 \\
\hline FeedCat & 1 & 23 & 20.1 & -7.4 & 1 & 10 & -9.0 & 2.3 \\
\hline LiveCat & 4 & 15 & 7.2 & -2.9 & 1 & 22 & -26.1 & 10.5 \\
\hline Hogs & 2 & 27 & 19.5 & -3.5 & & & & \\
\hline \multirow[t]{3}{*}{ All } & 35 & 21 & 21.1 & -5.4 & 8 & 16 & -14.3 & 4.2 \\
\hline & & & $(0.00)$ & $(0.00)$ & & & $(0.00)$ & $(0.01)$ \\
\hline & \multicolumn{8}{|c|}{ 2006-2011 } \\
\hline Corn & 1 & 17 & 12.1 & -3.0 & & & & \\
\hline Soy & 2 & 12 & 8.7 & -1.2 & 1 & 12 & -10.2 & 0.0 \\
\hline SoyOil & 3 & 12 & 10.5 & -3.4 & 1 & 21 & -24.0 & 9.9 \\
\hline \multicolumn{9}{|l|}{ Wheat } \\
\hline KWheat & 3 & 15 & 16.7 & -4.7 & & & & \\
\hline Сосоа & 1 & 17 & 14.6 & -0.8 & & & & \\
\hline Cotton & 1 & 57 & 52.5 & -21.6 & 1 & 22 & -22.6 & 4.6 \\
\hline Coffee & 1 & 10 & 10.4 & -1.2 & & & & \\
\hline Sugar & 4 & 19 & 17.2 & -4.0 & 1 & 19 & -16.0 & 2.0 \\
\hline FeedCat & 3 & 23 & 4.6 & -0.4 & 2 & 11 & -4.6 & 1.1 \\
\hline LiveCat & & & & & 1 & 11 & -4.3 & 1.4 \\
\hline Hogs & & & & & 2 & 13 & -7.4 & 3.5 \\
\hline \multirow[t]{2}{*}{ All } & 19 & 19 & 14.3 & -3.7 & 9 & 15 & -11.2 & 3.0 \\
\hline & & & $(0.00)$ & $(0.00)$ & & & $(0.00)$ & $(0.02)$ \\
\hline \multicolumn{9}{|c|}{ Differences between 1971-1976 and 2006-2011 } \\
\hline & -16 & -2 & -6.8 & 1.6 & 1 & -1 & 3.0 & -1.2 \\
\hline & & $(0.49)$ & $(0.07)$ & $(0.21)$ & & $(0.70)$ & $(0.44)$ & $(0.44)$ \\
\hline
\end{tabular}

Notes: Each explosive episode needs to last at least 10 days to be considered as a bubble. Bubbles are positive when the average price during explosive periods is higher than the price at bubble origination dates, and negative when the opposite is true. Average lengths and percentage price changes are presetned in the table. $\mathrm{N}$ refers to the number of bubble periods. Numbers in parentheses are p-values for the test that the mean or difference equals zero. Differences may not match due to rounding. 
(a) Soybean Oil December 2008 Contract

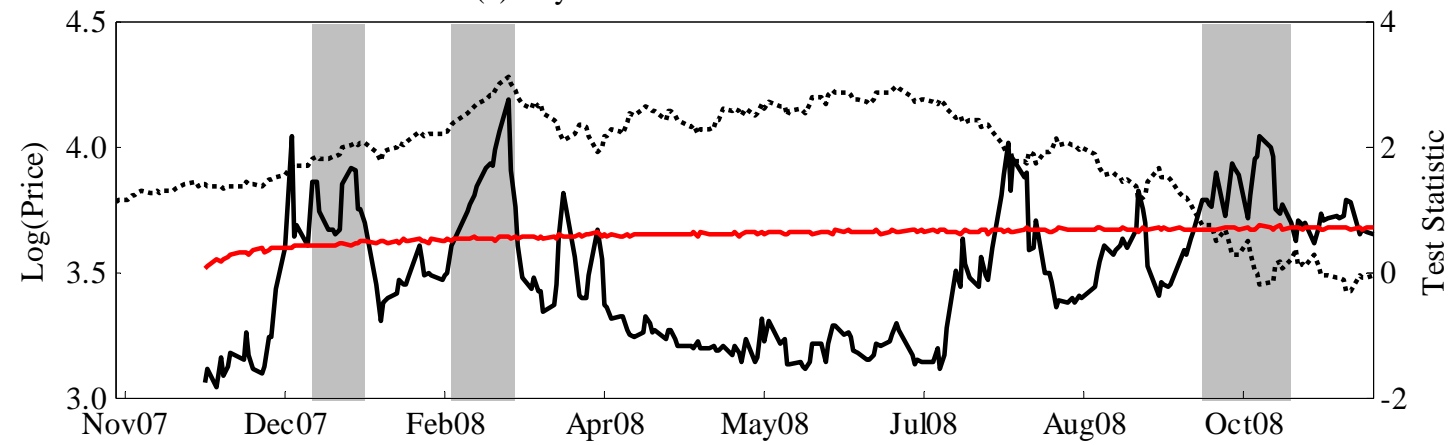

(B) Kansas Wheat July 2008 Contract

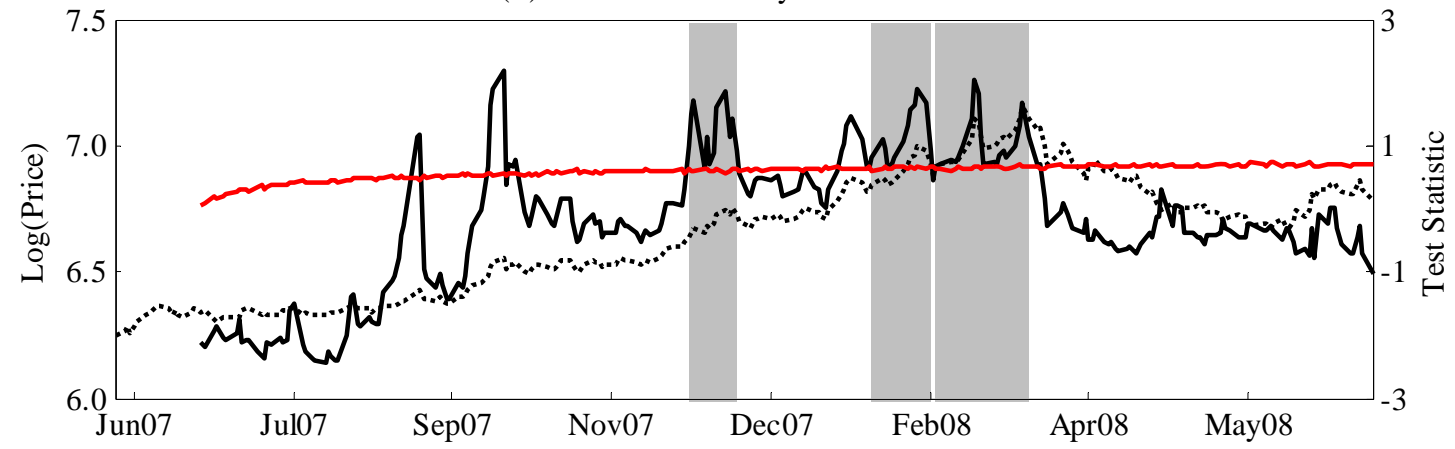

(c) Sugar October 2008 Contract

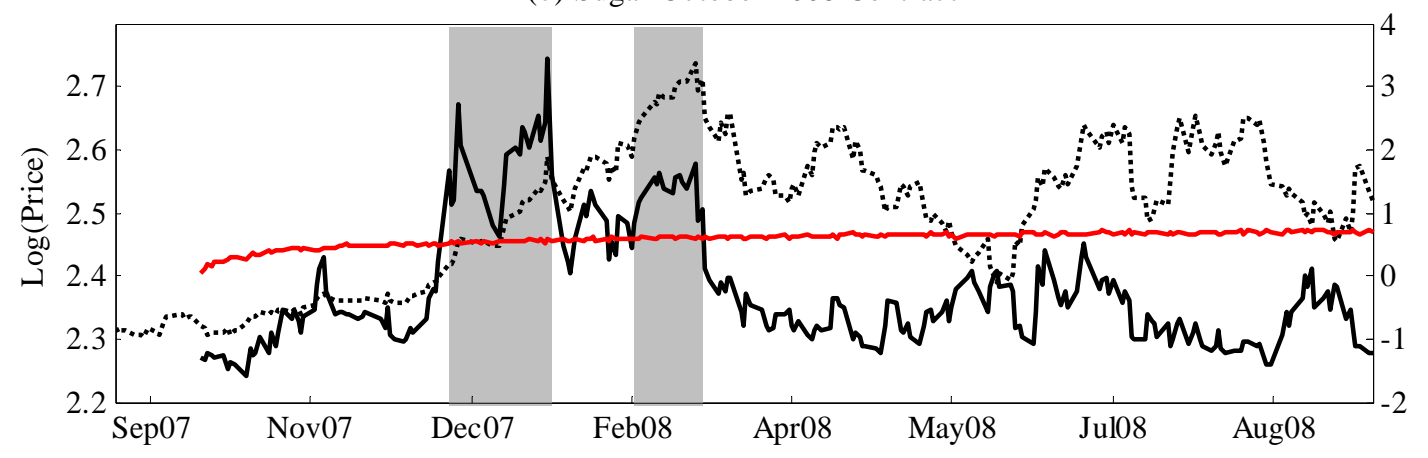

Log(price), left $\longrightarrow$ SADF, right $\longrightarrow$ CV95, right

Figure 1. SADF Date-Stamping Results for Selected Individual Agricultural Futures Contracts ( $h=10$ days) 

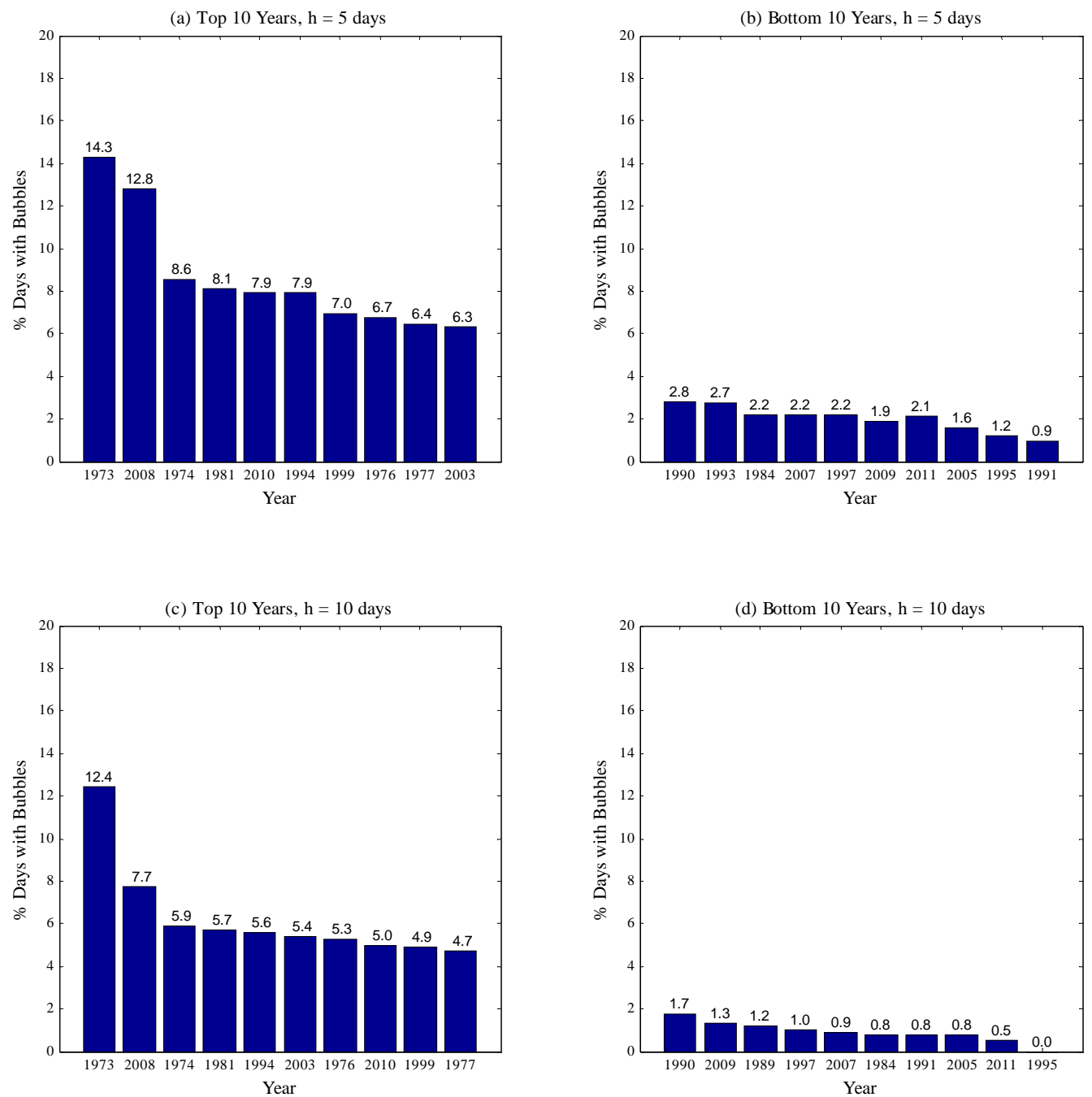

Figure 2. Percentage of Days with Bubbles Across All Agricultural Futures Contracts for Top and Bottom 10 Years, 1970-2011 
(a) Bubbles during 1970-1990 ( $\mathrm{h}=5$ days)

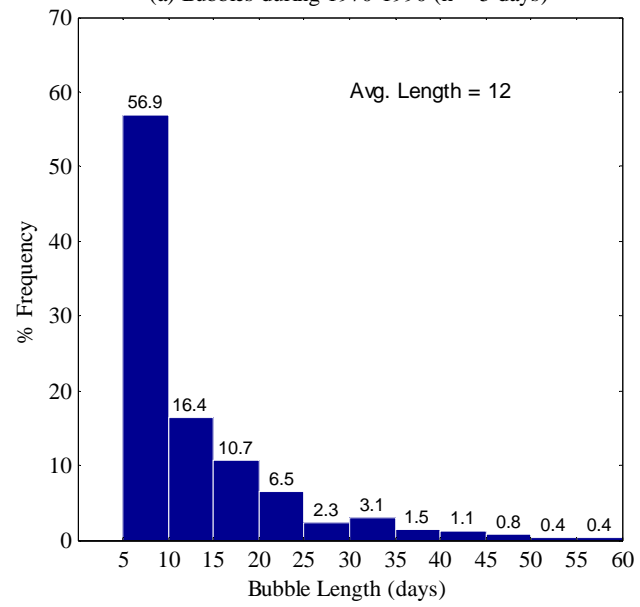

(c) Bubbles during 1970-1990 ( $\mathrm{h}=10$ days)

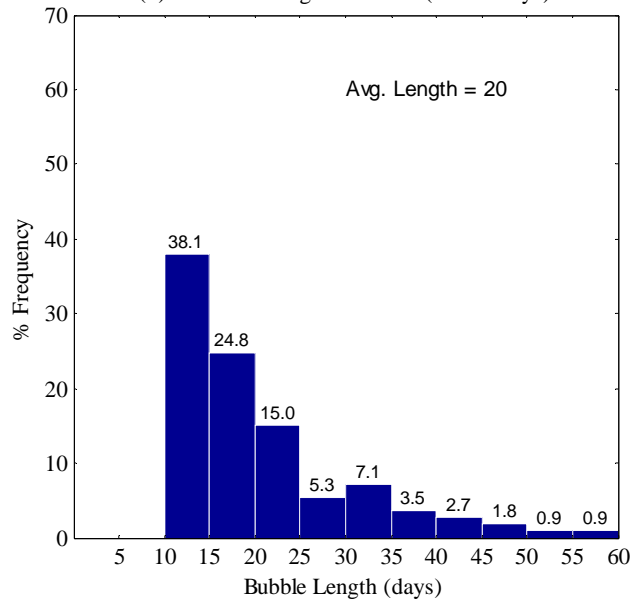

(b) Bubbles during 1991-2011 ( $\mathrm{h}=5$ days)

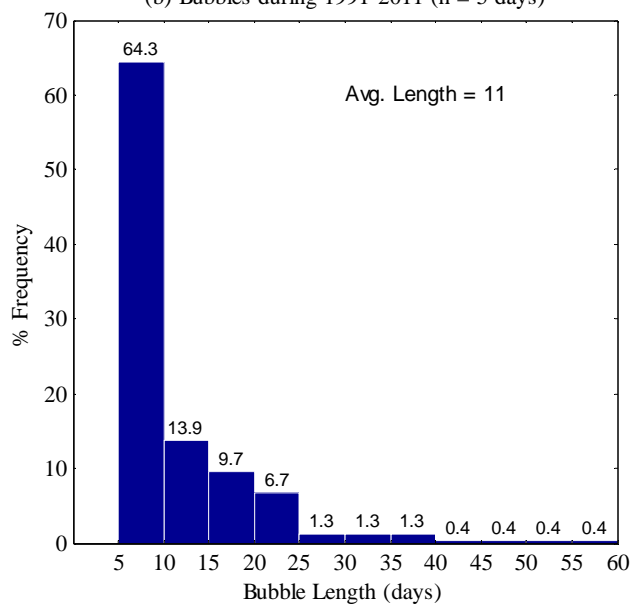

(d) Bubbles during 1991-2011 ( $\mathrm{h}=10$ days)

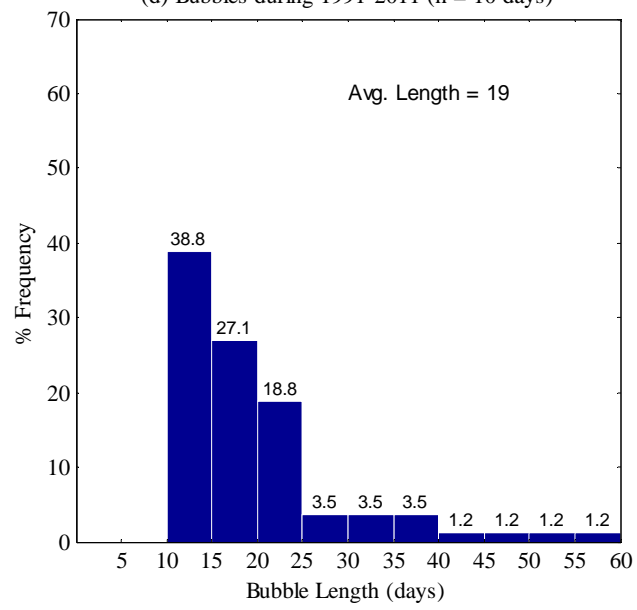

Figure 3. Frequency Distributions of Bubble Length for Individual Agricultural Futures Contracts, 1970-2011 
(a) Prices, SADFs and Critical Values

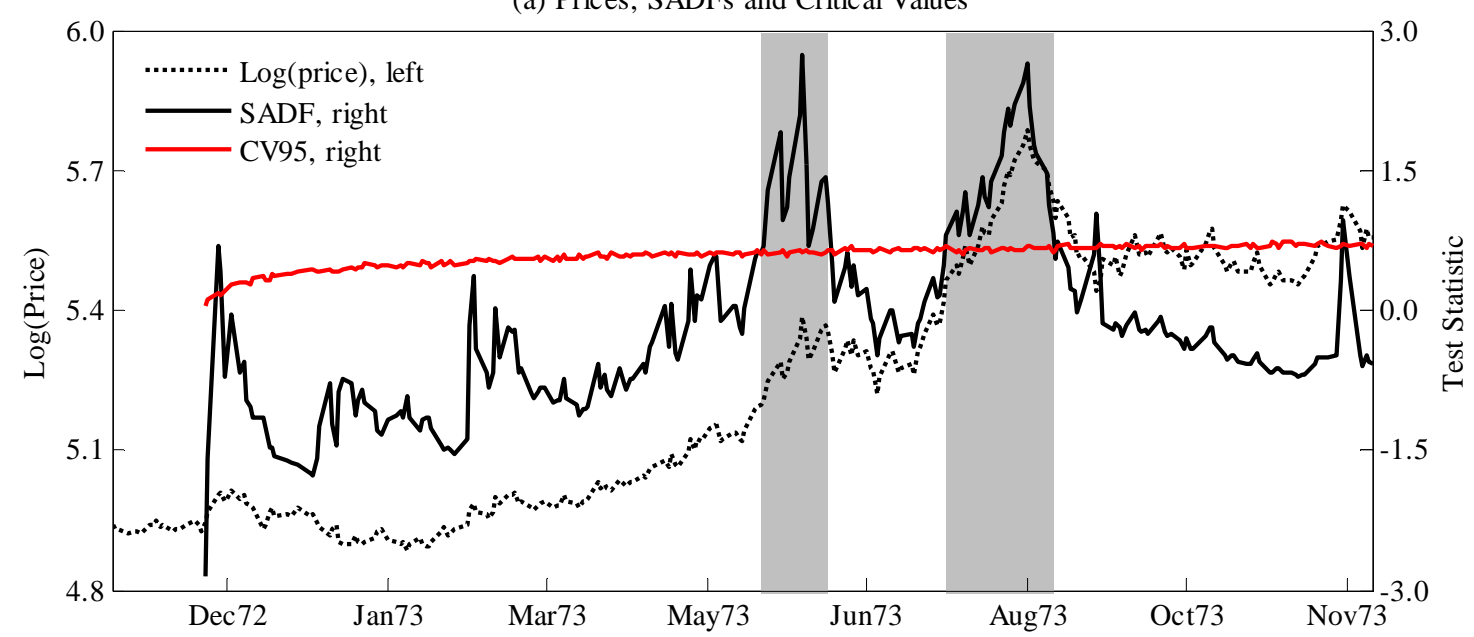

(b) Prices and $\beta_{\mathrm{r} 1, \mathrm{r} 2}$

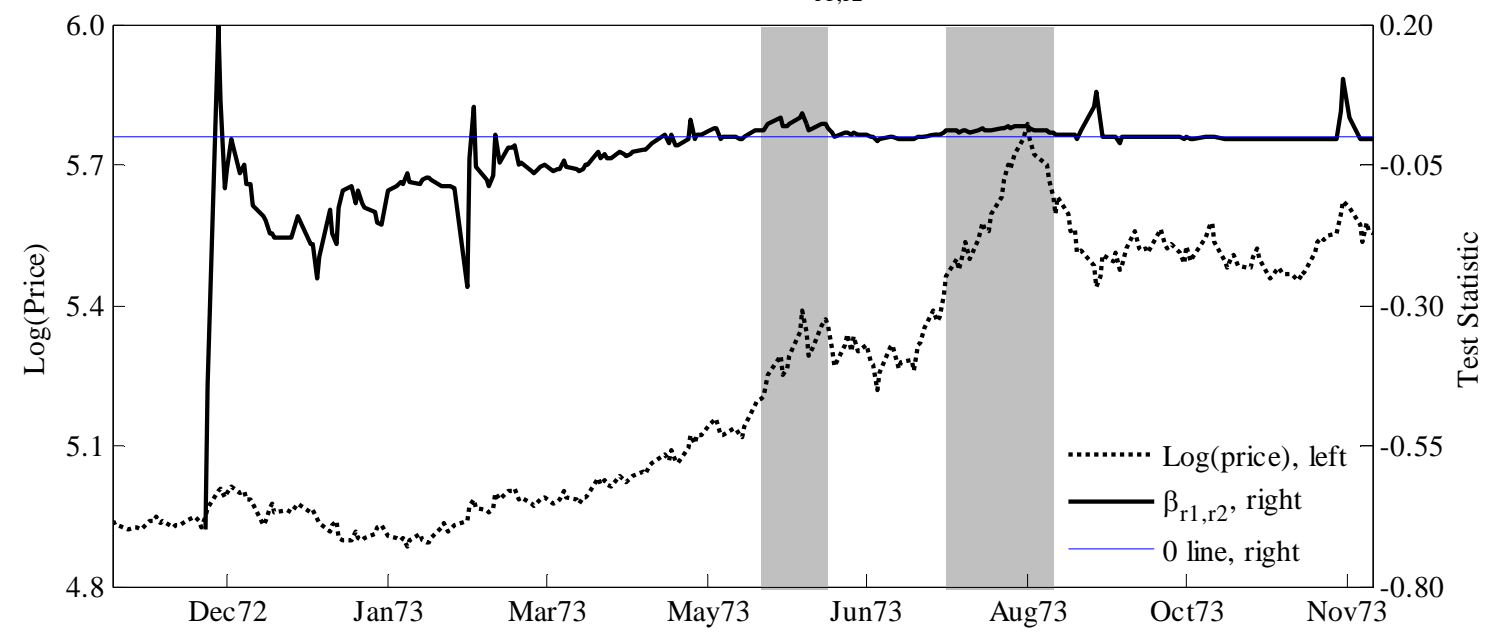

Figure 4. SADF Statistic, Regression Coefficients, and Explosive Periods for the December 1973 Corn Futures Contract 
(a) Soybean Oil Dec 1983

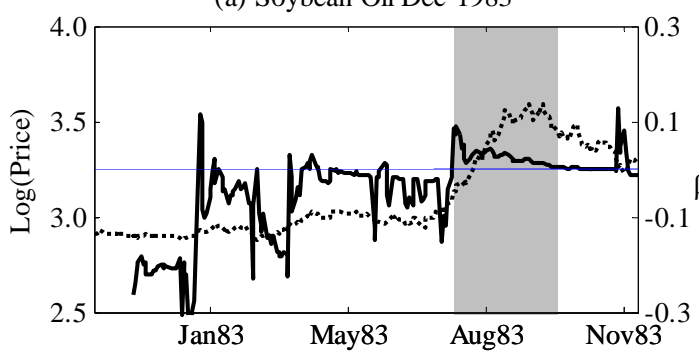

(c) Soybean Nov 1976

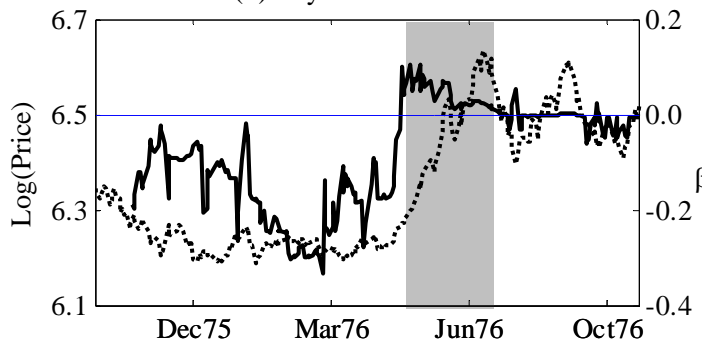

(e) Coffee Dec 1994

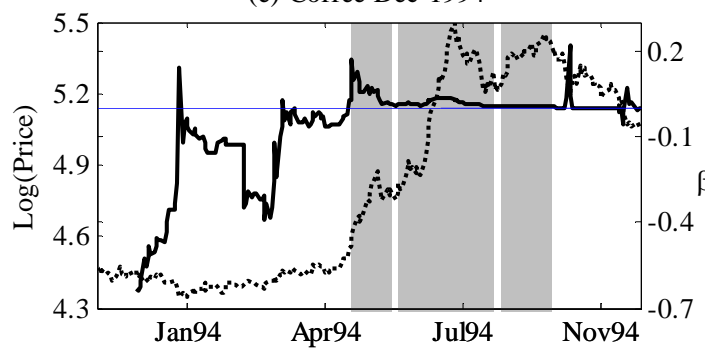

(g) Live Cattle Dec 2003

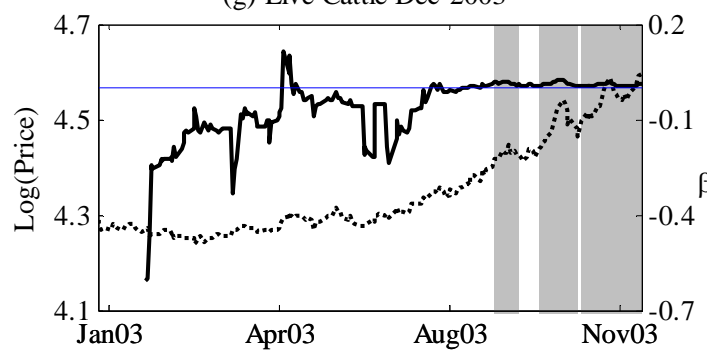

(b) Corn Dec 1985

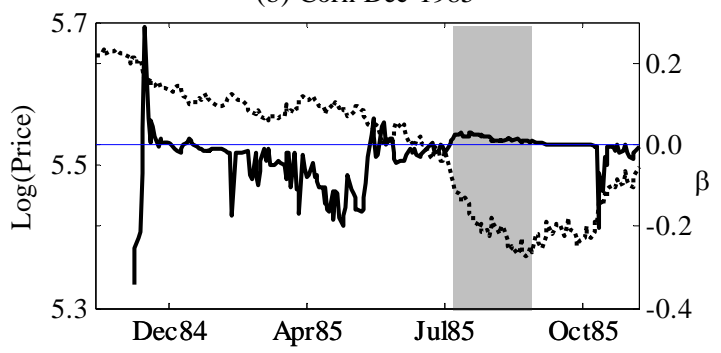

(d) Cocoa Dec 1973

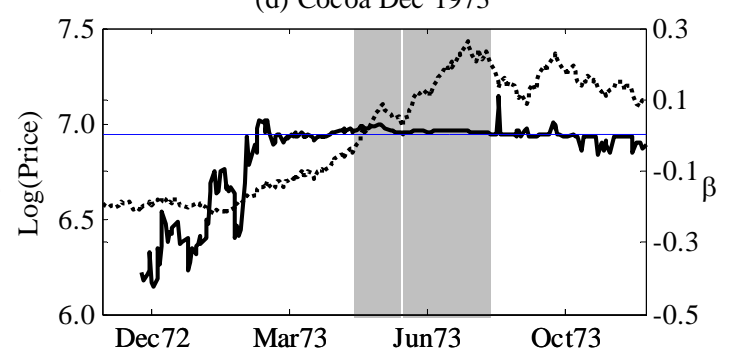

(f) Feeder Cattle Nov 2010

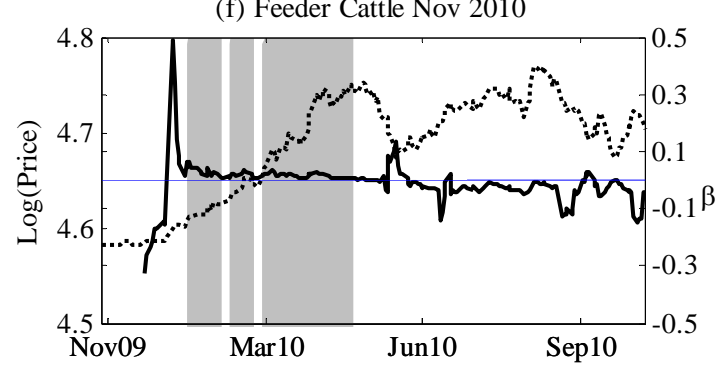

(h) Lean Hogs Dec 1994

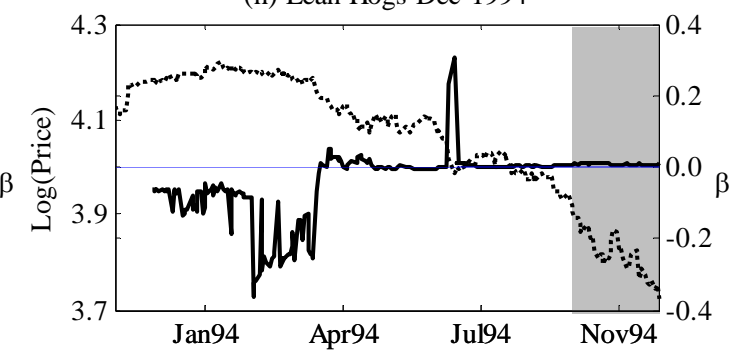

Log(price), left

$\beta_{\mathrm{r} 1, \mathrm{r} 2}$, right -0 line, right

Figure 5. Examples of Estimated Autoreression Coefficients during Bubble Episodes for Individual Agricultural Futures Contracts 
(a) Positive Bubbles during 1970-1990

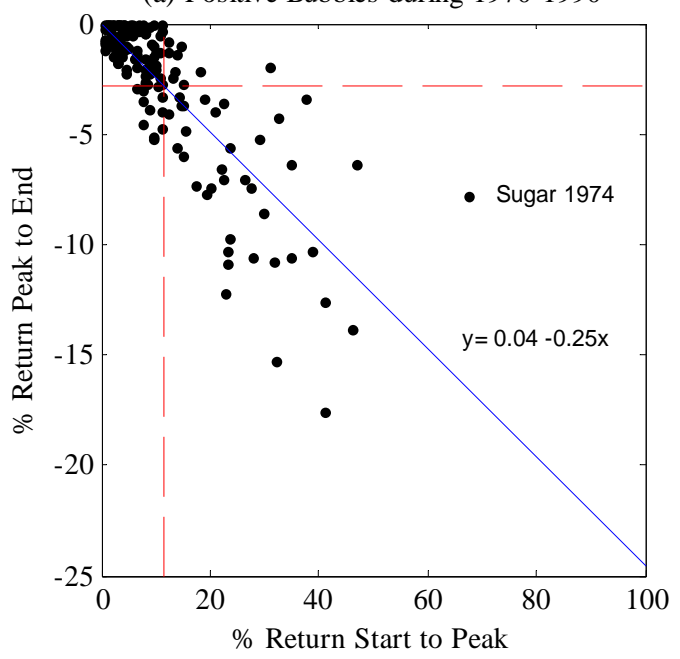

(c) Positive Bubbles during 1991-2011

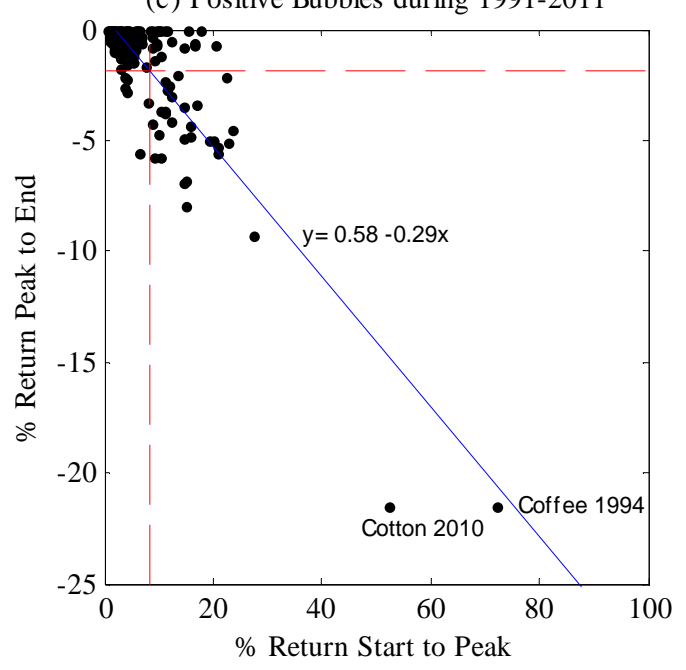

(b) Negative Bubbles during 1970-1990

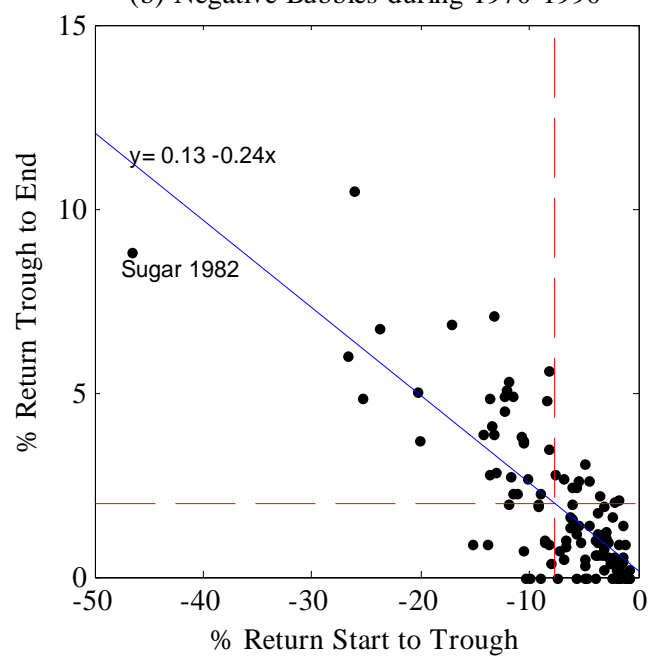

(d) Negative Bubbles during 1991-2011

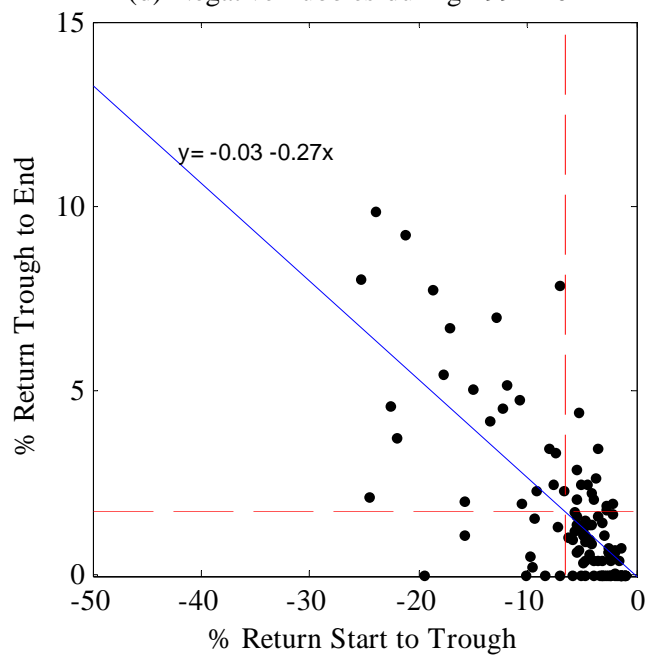

LS Regression

Figure 6. Cumulative Returns during Bubble Episodes for Individual Agricultural Futures Contracts, 1971-2011 ( $h=5$ days) 
(a) Positive Bubbles during 1970-1990

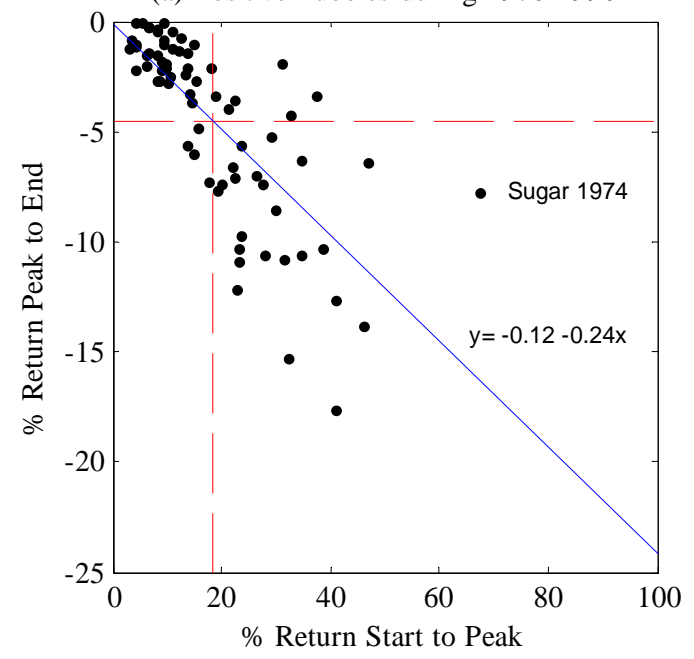

(c) Positive Bubbles during 1991-2011

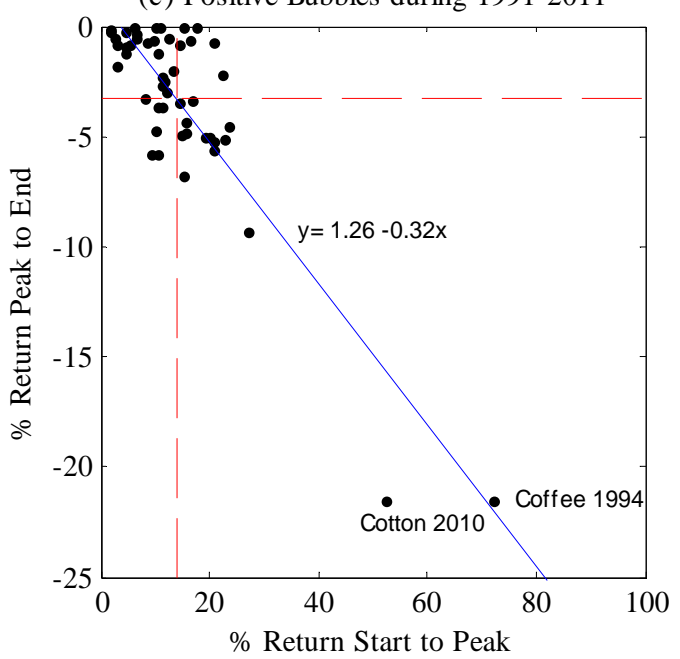

(b) Negative Bubbles during 1970-1990

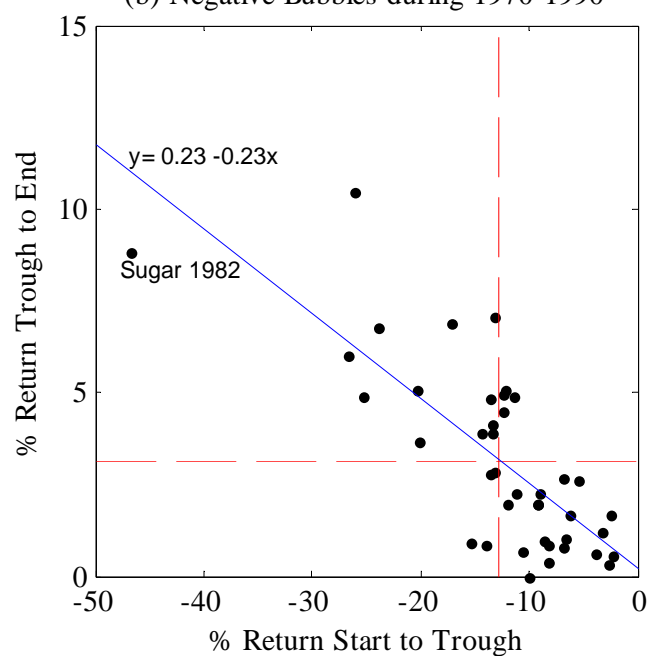

(d) Negative Bubbles during 1991-2011

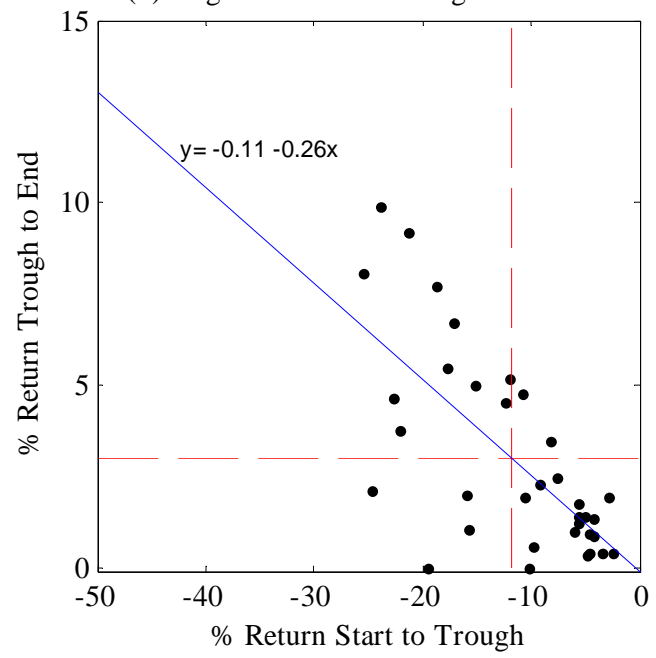

LS Regression

Figure 7. Cumulative Returns during Bubble Episodes for Individual Agricultural Futures Contracts, 1971-2011 ( $h=10$ days) 
(a) Prices, SADFs and Critical Values

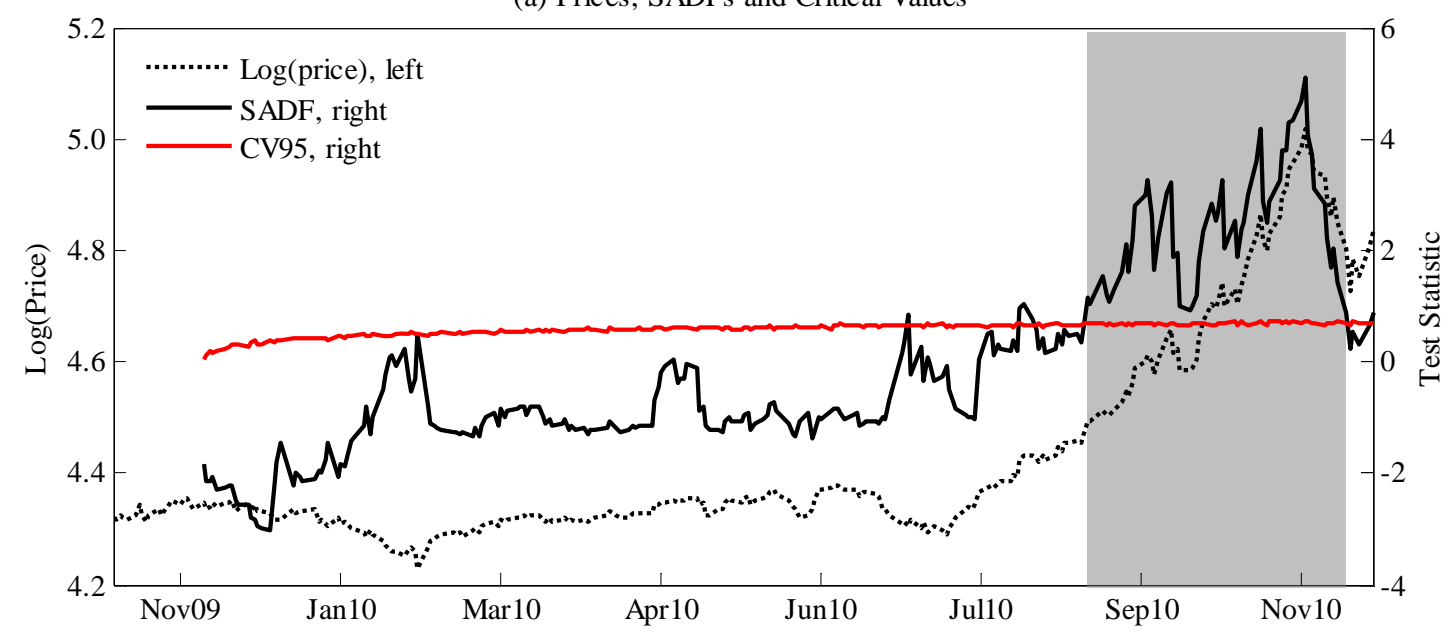

(b) Prices and $\beta_{\mathrm{r} 1, \mathrm{r} 2}$

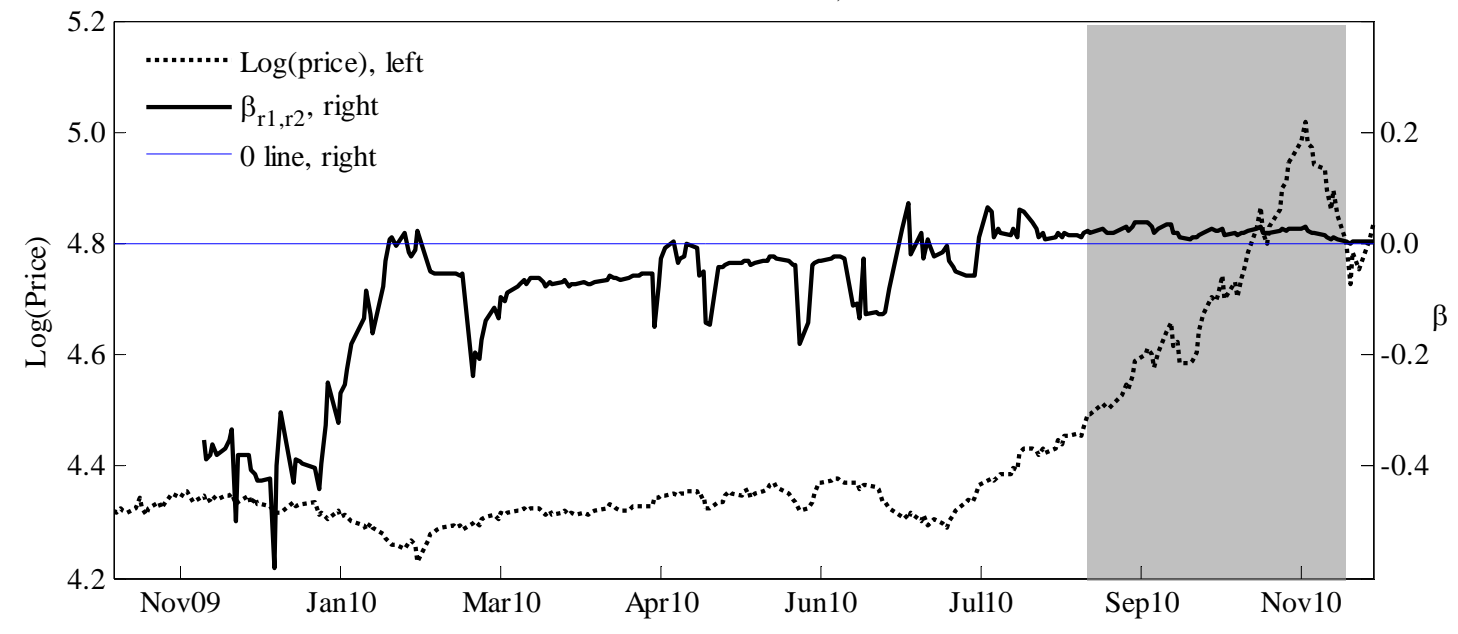

Figure 8. SADF Statistic, Regression Coefficients, and Explosive Periods for the December 2010 Cotton Futures Contract 